\title{
Variation and grammaticalisation in Bantu complex verbal constructions: The dynamics of information growth in Swahili, Rangi and siSwati
}

\author{
Hannah Gibson and Lutz Marten
}

\begin{abstract}
Many Bantu languages have a system of complex verbal constructions, where several verbal forms combine to describe a single event. Typically, these consist of an auxiliary and a main verb, and often tense-aspect marking and subject agreement is found on both forms. In this paper we develop a parsing-based, Dynamic Syntax analysis of complex verbal constructions in three Bantu languages - Swahili, Rangi and siSwati - and show how concepts of structural underspecification, accumulation of information and contextual update can be harnessed to explain the use of several verbal forms for the building of one semantic structure. At the heart of the analysis is the idea that structure established early in the parse can be 're-built' from subsequent lexical input as long as incrementality and information growth are respected. This correctly predicts the accumulation of tense-aspect information and the fact that multiple subject markers have to be interpreted identically, while maintaining a uniform pronominal analysis of Bantu subject markers. From a comparative perspective, we show that complex verbal constructions result from processes of grammaticalisation, and, especially with reference to the extensive auxiliary system of siSwati, we sketch different processes of lexical change underlying the stages of the grammaticalisation process.
\end{abstract}

\section{Introduction}

Bantu languages use a combination of tense-aspect markers and auxiliaries to encode temporal and aspectual distinctions. Simple constructions involve a single verb form inflected for tense and/or aspect information. Complex verbal constructions typically comprise of an auxiliary form inflected for subject information followed by a main verb, which may also be inflected for subject information or may appear in a 'bare', infinitival form. The restrictions on the ways in which these elements can combine and the resulting interpretations vary between languages. Complex constructions in the East African Bantu language Swahili employ the auxiliary - wa 'be'. This auxiliary form is inflected for tense information, whilst aspectual information is hosted by the main verb. The Tanzanian Bantu language Rangi also employs complex auxiliary constructions to encode specific tense-aspect distinctions, but uses different auxiliaries depending on the tense. For example $-r i$ ' 'be' is used in the present tense whilst -iise is used in the immediate future tense. ${ }^{1}$ In Rangi, as in Swahili, the main verb carries the aspectual information. The Southern African Bantu language siSwati similarly makes use of simple and complex constructions. However, siSwati has a substantially larger inventory of auxiliaries - some 30 forms - which are used to encode a broad range of meanings relating to tense, aspect and mood.

\footnotetext{
${ }^{1}$ Rangi has a 7-vowel system. We follow Stegen (2011) and Gibson (2013) where the vowels / / and $/ \mathrm{I} /$ are represented orthographically as $<\boldsymbol{\sharp}>$ and $<\dot{\mathbf{i}}>$ respectively.
} 
This paper explores auxiliary-main verb constructions in these three Bantu languages. It shows how temporal and aspectual information is encoded and combined in these construction types and across these languages more broadly. We adopt a Dynamic Syntax (DS, Kempson et al. 2001, Cann et al. 2005) approach. DS is a parsing-oriented framework which aims to articulate and substantiate the claim that human knowledge of language is essentially the ability to parse spoken language in context. Throughout, we show the ways in which auxiliary-main verb constructions in Swahili, Rangi and siSwati differ, as well as identifying areas in which a uniform analysis can be developed. The analysis of these constructions hinges on the concept of underspecification, with update available as the result of the accumulation of information provided by lexical input. Crucially, this takes place against a backdrop of contextual enrichment, albeit amidst highly specified restrictions.

Section 2 provides an introduction to the Dynamic Syntax theory. It presents the tools of the framework which are employed in the subsequent analyses. It also outlines the mechanisms of treegrowth and the ways in which structure unfolds throughout the course of the parsing process. Section 3 constitutes an analysis of complex verbal constructions in Swahili, whilst in Section 4 attention is turned to Rangi, and siSwati is the focus of Section 5. Section 6 constitutes the conclusion, highlighting the findings of the paper along with routes for possible further enquiry.

\section{Dynamic Syntax}

\subsection{The tools of the framework}

Dynamic Syntax is a formal model of utterance interpretation that aims to articulate and substantiate the claim that human knowledge of language is essentially the ability to parse spoken language in context. Syntax is viewed as a parsing device which constitutes the process of incrementally building semantic representations from lexical and contextual information (Kempson et al. 2001, Cann et al. 2005, Kempson et al. 2011). This process of structure building is goal-driven and incremental. Throughout the process, information is accumulated, underspecified content is enriched and requirements are resolved with a single level of semantic representation adopted. Since parsing and production take place on an incremental basis, information once established cannot be undone, although requirements can be left outstanding at any of the intermediate stages in the processes. However, by the end of the parsing process, no requirements can be left unfulfilled. Crucially in DS, well-formedness depends on both the final tree and the steps which have led to its development.

Dynamic Syntax assumes a single level of semantic representation which is modelled through binary semantic trees. Parsing takes place on a left-to-right basis with a direct and dynamic mapping from linearly-ordered words to structured semantic representations on these trees. The Logic of Finite Trees (LOFT, Blackburn and Meyer-Viol 1994, Kempson et al. 2001) is used to annotate tree nodes and makes it possible to explicitly state relations that hold between the tree nodes. An overview of the tree annotations employed in this paper is provided in (1) below. 


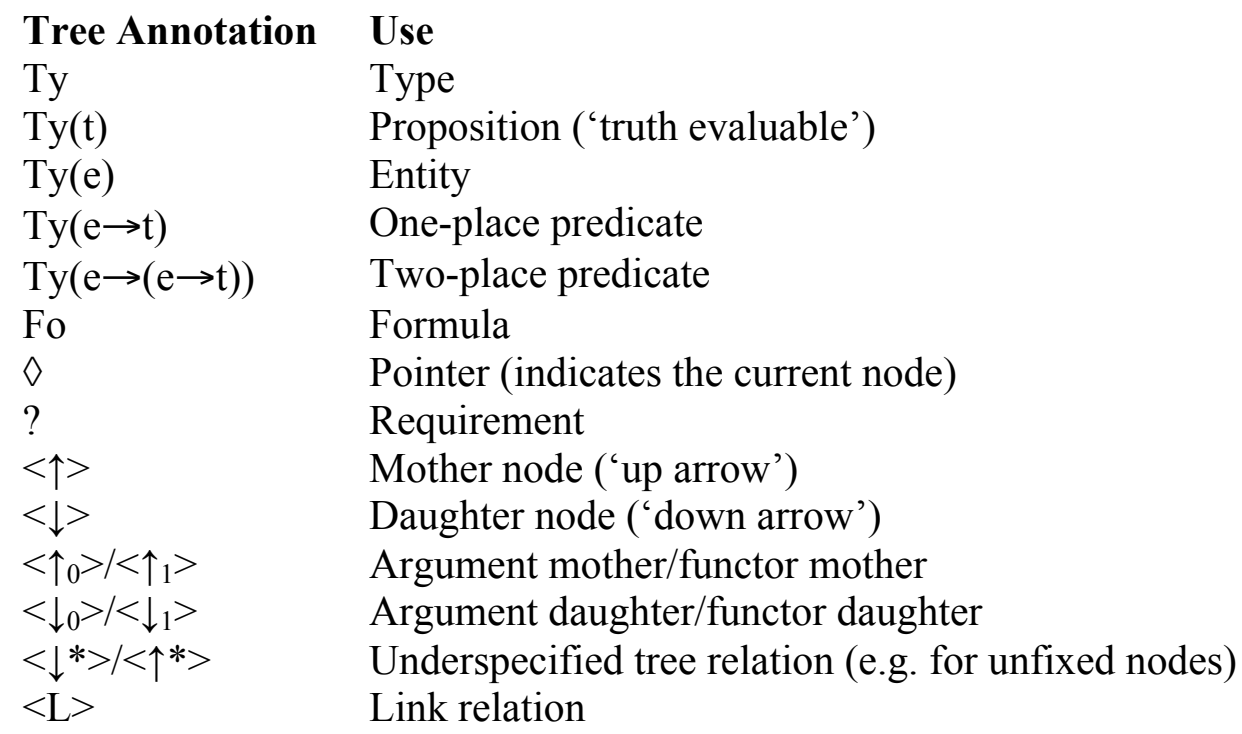

\subsection{The dynamics of tree growth}

Tree growth in Dynamic Syntax takes place in three ways; through computational rules, through lexical rules and through pragmatic update. Computational rules are the basic mechanism by which semantic trees are constructed. The rules enable the development of one partial tree description into another partial tree description. The computational rules are universally available across languages and can apply at any stage during the derivation although they require specified conditions (known as triggers) to be present in the tree or at the node under development. The second mechanism for tree growth is through lexical input. Lexical items encode lexical actions which map one tree description to the next. Each word or morpheme has its own lexical entry which provides distinct information about how the parse and associated semantic trees can unfold. Lexical entries are of an IF-THEN-ELSE format. The IF clause states the conditions which need to hold at the current node in the tree in order for the lexical action to be performed. If the conditions are met, the set of lexical actions in the THEN statement is performed, which may include the building of new nodes ('make'), the shifting of the actions from the current node to another node ('go'), or the decoration of a node with new information ('put'). If the triggering conditions are not met, an ELSE statement applies, often indicating that the parse cannot proceed and the actions abort. Lexical input is therefore very powerful, serving to introduce requirements, annotate nodes and induce tree structure. The format of the lexical rules is provided in (2) below.

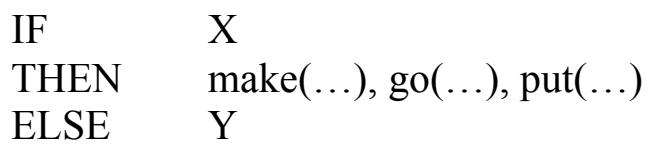

Finally, pragmatic enrichment occurs throughout the process of tree growth and is the result of information made available by the context. This may be the immediate local context (i.e. within the same semantic domain), or might be recoverable from the broader linguistic or non-linguistic context. Underspecified information may be enriched through further lexical information or from the provision of pragmatic information made available by the context, and all underspecified values must be 
updated to full representations before the parse is complete.

The parsing process is represented through the incremental growth of binary semantic trees. The information on the trees is updated as each word or morpheme is parsed. Dynamic Syntax derivations therefore show transitions from a minimal tree (which is always the starting point) through a series of partial trees until a complete tree is formed. The final, complete tree represents the propositional formula which is established as the final output of the interpretation process. However, all of the information represented in the 'intermediate' partial trees is as important as the snapshot of the final tree, showing the way in which semantic content is processed and combined, and propositional structure established. An overview of the stages involved in parsing an utterance such as John likes Sally is provided below.

The first tree in any DS derivation is introduced by a rule known as the AXIOM. The AXIOM (3a) represents the expectation for some meaningful content to be provided by the speaker and introduces the requirement for the establishment of a proposition $($ ? Ty $(t))$. The pointer $(\diamond)$ indicates the current node under development. Each (partial) tree has exactly one current node so the pointer will only be present on one node at any given time. Pointer movement is tightly restricted, and is only licensed by the application of a computational rule or lexical actions. In (3b) we assume that computational rules allow the projection of an argument-requiring node with the requirement for an expression of Ty(e), which becomes the current node. ${ }^{2}$

John likes Sally

a. $\quad$ Ty $(\mathrm{t}), \diamond$

b.

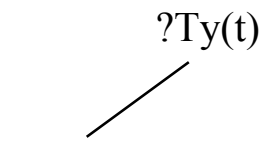

?Ty(e), $\diamond$

The requirement for an argument (?Ty(e)) is fulfilled upon hearing the subject expression John, and a predicate-requiring node is licensed by computational rules (3c). The lexical item likes is transitive and licenses the construction of an additional $\mathrm{Ty}(\mathrm{e} \rightarrow(\mathrm{e} \rightarrow \mathrm{t}))$ node, annotated with Fo(like'), and its associated requirement for a Ty(e) object (3d).

c.

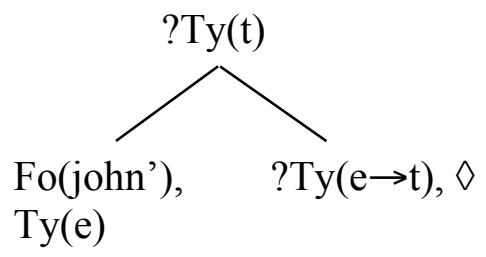

d.

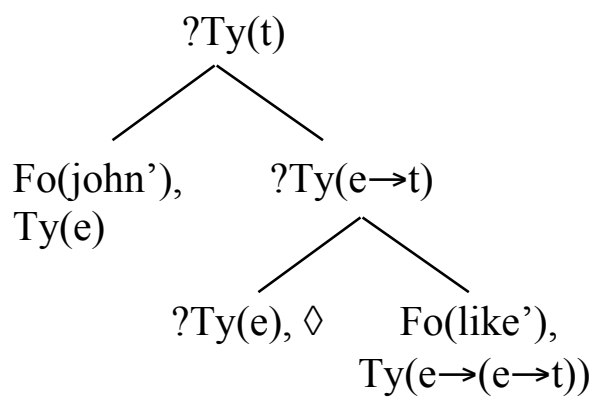

Parsing Sally provides the annotation for the object node and fulfils the requirement at this node. With all of the requirements fulfilled, the information is compiled up the nodes and the tree is complete (3f).

\footnotetext{
${ }^{2}$ Note that the trees are semantic representations, and do not represent word-order. By convention, predicates annotate nodes on the right-hand side of the tree whilst arguments appear on the left-hand side of the tree. Word order is expressed in the system by the growth of the semantic representations from the words encountered and is reflected in the licensed transitions during tree growth.
} 
e.

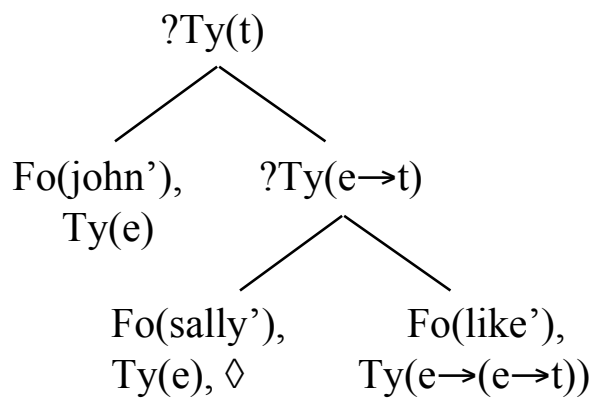

f.

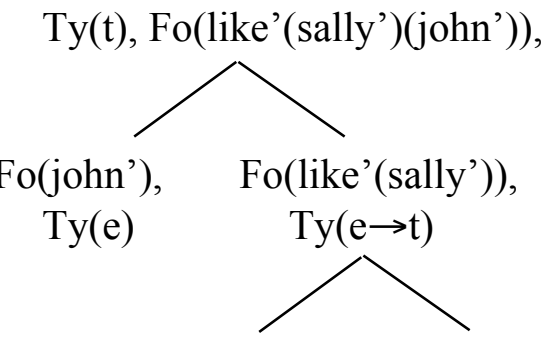

Fo(sally'), Fo(like'),

Ty(e) $\quad$ Ty $(e \rightarrow(e \rightarrow t))$

Ways of introducing information early (at the left periphery) or late (at the right periphery) also exist. The tree nodes shown above all have fixed tree node addresses from the outset. However, unfixed nodes are nodes that are not associated with any fixed position in the tree at the point at which they are introduced. These have a temporary underspecified tree node address which will be updated to a fixed address as additional information is made available during the parsing process, and necessarily before the parse is complete. As such, unfixed nodes are used to represent structural underspecification. There are two types of structurally underspecified nodes - 'regular' unfixed nodes which are generally underspecified with respect to the root node with the tree node address $\langle\uparrow *>$ ?Ty(t), as in (4b), and locally unfixed nodes which specify one fixed argument relation while being otherwise unfixed, with the tree node address $\left\langle\uparrow_{0}\right\rangle\left\langle\uparrow_{1} *\right\rangle$ ? Ty $(\mathrm{t})$. This more restrictive definition limits their possible interpretation to the local predicate-argument domain (4c). Additionally, Link structures can also be built which connect two otherwise independent (partial) trees through the requirement for the presence of a shared term (4d).

a. Fixed node

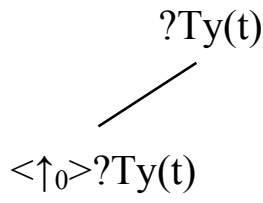

c. Locally unfixed node

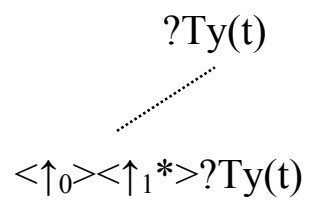

b. Unfixed node

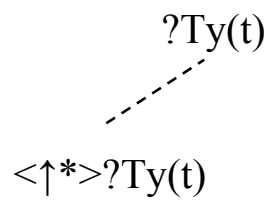

d. Linked node

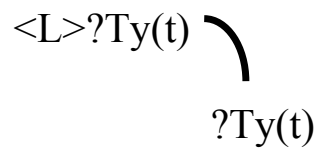

Tree nodes are defined with respect to one another; this means that, for example, projecting a left-daughter node, and then another left-daughter node of the same node will merely result in the construction of the same node again: There will only be one left-daughter node. This means that the same node can be built several times. As long as the information holding at the node is consistent, this is fine, and we will make use of this formal aspect of the system in the analysis of complex verbal constructions developed in the next sections. Underspecification is considered to be the property of natural language that allows the introduction and manipulation of incomplete information at any (and every) stage in the production/parsing process. As we will see 
throughout the paper, this is a powerful concept which must be subject to appropriate restrictions in order to accurately model what is permissible - and what is not permissible - in any given language. Context is also central to interpretation, and strings of words are interpreted and enriched by the context against which they are presented.

\subsection{Swahili clause structure in Dynamic Syntax}

We assume that inflectional morphemes provide their own lexical information and make distinct contributions to the process of structure building. Bantu languages exhibit subject pro-drop and an inflected verb form is regularly sufficient for the establishment of complete propositional structure. Take for example the Swahili utterance walifika 'they arrived' (5). Given the right conditions (i.e. the presence of a referent recoverable from context), such an utterance is sufficient to enable the establishment of complete propositional structure with no outstanding requirements. The stages involved in this process are outlined below. ${ }^{3}$

$$
\begin{aligned}
& \text { Wa-li-fik-a } \\
& \text { SM2-PAST-arrive-FV } \\
& \text { 'They arrived' }
\end{aligned}
$$

For Swahili, we assume that the class 2 subject marker $w a-$ - which we analyse as a pronominal element (cf. Bresnan and Mchombo 1987) - projects a locally unfixed node (Cann et al. 2005, Marten 2011). The analysis of the Swahili subject marker as projecting a locally unfixed node is related to its status as a clitic and in this regard it can be considered analogous to the analysis of Romance clitics developed in Cann et al. (2005). It is also motivated by the DS analysis of the so-called subject marker in constructions such as locative inversion and subject object reversal, as well as of Bantu passives (cf. Marten and Gibson 2015). In the case of wa-, this locally unfixed node is decorated with the pronominal metavariable $\mathrm{Fo}\left(\mathbf{U}_{\mathrm{WA}}\right)$, reflecting the class restriction of the possible referents to class 2 (human plural). The lexical actions encoded in the subject marker also introduce the requirement ? $\exists \mathrm{x}(\mathrm{Fo}(\mathrm{x}))$ which states that this metavariable (although its interpretation is still underspecified) has to be updated to a full formula value before the derivation is complete. The conditions for the application of the lexical actions are captured in the IF statement, namely that the current node has the requirement ?Ty $(\mathrm{t})$ and that no fixed structure exists at this stage (formalised by employing the falsum as $[\downarrow] \perp$, i.e. no fixed nodes exist below this node $)^{4}-$ ensuring that the subject marker comes first in the verbal form: ${ }^{5}$

\footnotetext{
${ }^{3}$ The following abbreviations are used throughout: Numbers 1, 2, 3 etc. in glosses refer to noun classes. $\mathrm{ALT}=$ alterative, $\mathrm{APPL}=$ applicative, $\mathrm{AUX}=$ auxiliary, $\mathrm{CAUS}=$ causative, $\mathrm{CONN}=$ conjunction, $\mathrm{COP}=$ copula, $\mathrm{DEM}=$ demonstrative, $\mathrm{DT}=$ disjoint, $\mathrm{FV}=$ final vowel, $\mathrm{INF}=$ infinitive, $\mathrm{LOC}=$ locative, $\mathrm{NEG}=$ negative, $\mathrm{OM}=$ object marker, $\mathrm{S}=$ subject, $\mathrm{SBV}=$ subjunctive, $\mathrm{SG}=$ singular, $\mathrm{SIT}=$ situative, $\mathrm{SM}=$ subject marker, PASS $=$ passive, PAST $1=$ recent past, PAST $2=$ distant past, $\mathrm{PERF}=$ perfective, $\mathrm{PL}=$ plural, $\mathrm{PP}=$ personal pronoun, $\mathrm{PROG}=$ progressive, $\mathrm{Q}=$ interrogative, $\mathrm{REL}=$ relative pronoun.

${ }^{4}$ The requirement that no daughter nodes exist at the node is a description of the node at this particular stage in the parse - when the lexical information from $w a$ - is accessed - but does not prevent the development of fixed daughter nodes during subsequent parsing steps.

${ }^{5}$ We will see below that the lexical entry for subject markers is more complex than this, and will provide more lexical information in the place at present marked by '...'.
} 
(6)

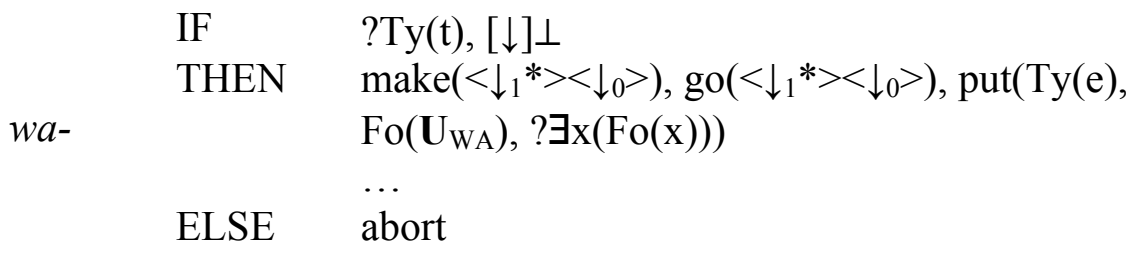

The partial tree that results from the lexical actions induced upon parsing $w a$ - is shown in (7). The dotted line indicates that this is a locally unfixed node - a tree node relation which is captured formally through the annotation $\left\langle\uparrow_{0}\right\rangle\left\langle\uparrow_{1} *\right\rangle$ ? Ty $(\mathrm{t})-$ which has an as yet underspecified relationship to the root node.

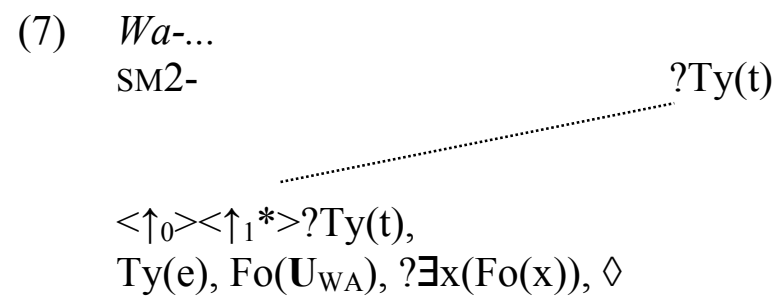

The update of the metavariable placeholder $\mathbf{U}_{\mathrm{WA}}$ to a full formula value in this example is a pragmatically-driven process by which the lexically provided metavariable is enriched with a term established through context. Therefore, $\mathbf{U}_{\mathrm{wA}}$ can appropriately be substituted by a concept such as watalii 'tourists', which for this example we assume to be present in the context, and whose semantics is compatible with those of class 2 . However, although the process of substitution enables update to a full formula value, the tree node address of the node remains unspecified - and therefore unfixed - until a later point in the parsing process (8).

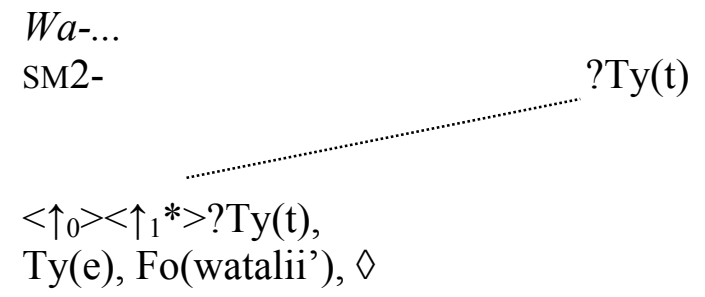

An alternative way of updating the formula value would be through merge with an overt subject expression if one was provided. Since DS trees are semantic representations, the update of the underspecified formula value through contextual information or through a lexically provided subject yields the same result. In both cases, the formula value is replaced by a contentful expression.

We assume that the tense marker makes a temporal contribution to the parse represented by an annotation at the root node (in this case Tns(PAST)). ${ }^{6} \mathrm{We}$ also propose that the Swahili tense marker $l i$ - builds a fixed subject node and a fixed predicate node, reflecting the historical origins of tense-aspect markers in auxiliary

\footnotetext{
${ }^{6}$ This annotation does not constitute a formal analysis of tense. Gregoromichelaki (2006) proposes the introduction of a situation argument as a formal mechanism of the representation of tense-aspect information in the DS tree. In a similar vein, Cann (2011) provides a comprehensive analysis of the English auxiliary system, employing the situation argument node to explore the temporal and aspectual properties of the system. In the interests of brevity, in the current discussion we maintain a pro tem representation of tense information made available in the parse which appears as an annotation at the root node.
} 
and lexical verbs (cf. Cann et al. 2005, Marten et al. 2008, and Gibson 2013 for DS analyses of Bantu tense-aspect markers from this perspective). ${ }^{7}$ The actions induced upon parsing the tense marker $l i$ - can be seen in the lexical entry in (9) below.

$$
\begin{aligned}
& \text { IF } \quad \text { TTy }(\mathrm{t}),<\downarrow_{0}>\perp,<\downarrow_{1} *><\downarrow_{0}>\text { Ty }(\mathrm{e}) \\
& \text { li- } \quad \text { THEN } \operatorname{put}(\operatorname{Tns}(\mathrm{PAST})), \operatorname{make}\left(<\downarrow_{1}>\right), \operatorname{go}\left(<\downarrow_{1}>\right), \operatorname{put}(\text { ? Ty }(\mathrm{e} \rightarrow \mathrm{t})) \text {, } \\
& \operatorname{go}(<\uparrow>), \operatorname{go}\left(<\downarrow_{0}>\right) \text {, put }(\text { ?Ty }(\mathrm{e})) \\
& \text { ELSE abort }
\end{aligned}
$$

The IF clause of (9) states the conditions under which the lexical actions in the THEN statement can be performed: The current node needs to be the root node at which ?Ty(t) holds, no fixed subject node must have been built yet and a locally unfixed node needs to be present at the node under development. This means that the tense marker $l i$ - has to be parsed before any fixed structure has been built, ensuring that it is parsed after a subject marker (which introduces the locally unfixed node) and prevents, for example, verb forms with two pre-stem TAM markers (which is not possible in Swahili). If these conditions are met, the lexical actions license the building of a fixed predicate node with the requirement ?Ty $(\mathrm{e} \rightarrow \mathrm{t})$ and of a fixed subject node with ?Ty(e). The resulting structure can be seen in (10) below.

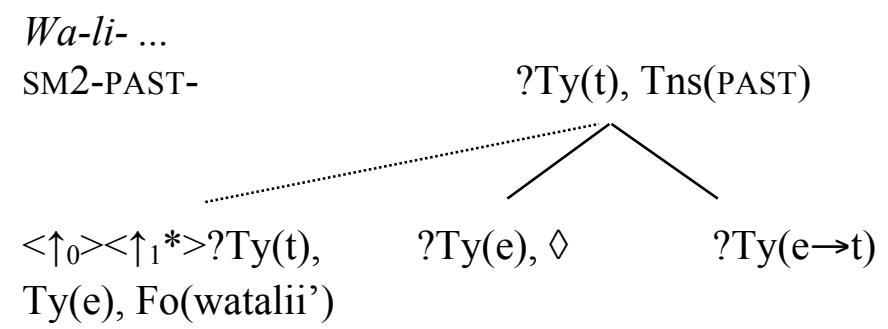

At this point, the locally unfixed node annotated with the subject information can merge with the fixed subject node, enabling the establishment of a fixed tree node address for the subject expression Fo(watalii').

(11) Wa-li-...

SM2-PAST-

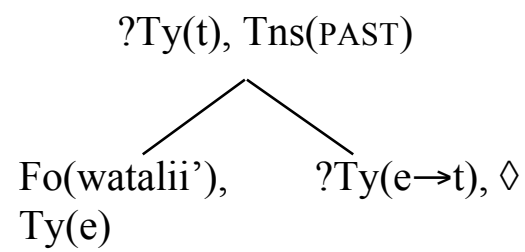

The next element to be parsed is the verb stem -fik- 'arrive'. Verbs in Swahili are parsed after tense-aspect information is supplied and a skeletal predicate-argument structure has been built, as seen in (11). In the lexical entries for verbs this is reflected in the IF statement, which shows the presence of a node with ?Ty $(\mathrm{e} \rightarrow \mathrm{t})$ as a necessary trigger for the verb's actions (12). The predicate node is then decorated with lexical

\footnotetext{
${ }^{7}$ As we will see below in the discussion on siSwati auxiliaries, tense markers such as Swahili $l i$ constitute a late stage in the grammaticalisation process from main verb via auxiliary to tense marker. We will discuss later in the paper the different lexical contributions of tense markers and lexical verbs to structure building and how this can be used to model the process of grammaticalisation of auxiliary verbs and its relation to suffixal-to-prefixal tense marking morphology.
} 
information from the verb as specified in the lexical entry. In the case of a transitive predicate, parsing the verb would also introduce a fixed object node.

$$
\begin{array}{lll} 
& \text { IF } & \text { ?Ty }(\mathrm{e} \rightarrow \mathrm{t}) \\
-f i k- & \text { THEN } & \operatorname{put}(\operatorname{Ty}(\mathrm{e} \rightarrow \mathrm{t}), \text { Fo(fik')) } \\
& \text { ELSE } & \text { abort }
\end{array}
$$

Parsing the verb stem introduces the lexical semantic information about the predicate, enabling the update of the information on the predicate node to a full formula value Fo(fik'). The resulting tree is shown in (13).

$$
\begin{aligned}
& \text { Wa-li-fik ... } \\
& \text { SM2-PAST-arrive }
\end{aligned}
$$

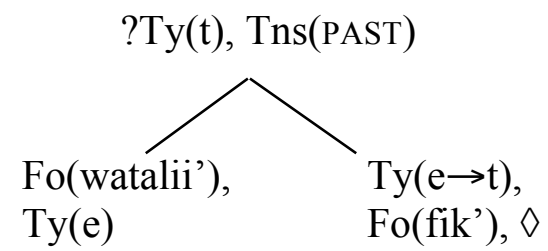

After parsing the final vowel $-a$, the information is compiled and results in the final tree shown in (14). Parsing the obligatory final vowel results in the introduction of the so-called 'bottom restriction' $([\downarrow] \perp)$ on the lowest predicate node, preventing any further structure from being built from the node. Furthermore, parsing the final vowel moves the pointer to the next higher node, so that the predicate node can no longer be further developed, and no further structure or any further valency-changing modifications of the predicate are possible. ${ }^{8}$ As can be seen upon examination of the tree, at this final stage in the derivation, all of the requirements have been resolved and all of the nodes are annotated with fully specified formula and type values.

$$
\begin{aligned}
& \text { Wa-li-fik-a} \text { 'They (i.e. the tourists) arrived' } \\
& \text { SM2-PAST-arrive-FV }
\end{aligned}
$$

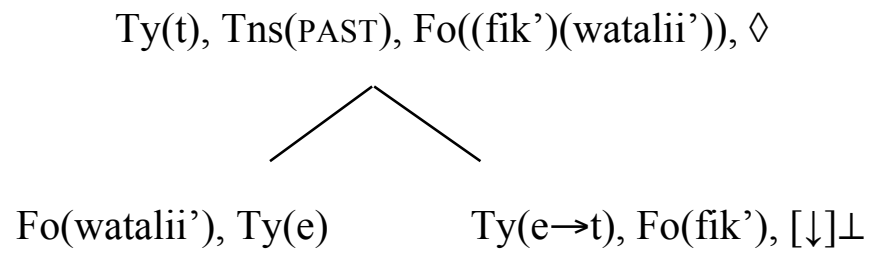

The final tree shows the predicate-argument structure of the proposition, as well as semantic annotations such as tense. However, morpheme and word order is not reflected in the tree, but can be seen from the sequence of transitions and partial trees leading to the development of the final tree. The sample derivation has shown the way in which lexical information provided by tense markers and verbs in Swahili combines, and, more generally, how processes of underspecification and update lead to the accumulation of information and the eventual establishment of the proposition expressed. In the following sections, we develop analyses of complex verbal constructions involving auxiliaries and main verbs in Swahili, Rangi, and siSwati,

\footnotetext{
${ }^{8}$ The rationale for this analysis is that valency-changing suffixes in Bantu occur after the verb root, but must appear before the final vowel.
} 
employing the same tree-building concepts.

\section{Swahili complex verbal constructions}

Like in most Bantu languages, expression of tense-aspect-mood distinctions in Swahili involves both morphological and syntactic marking. As seen in the previous section, there are morphological tense-aspect-mood markers such as the past marker $l i$ - which appear as part of inflected verb forms. In addition, syntactically complex verb forms are constructed by using auxiliary verbs, in particular -wa 'be' (or the alternative form kuwa, cf. Marten 2002). ${ }^{9}$ In this section, we will discuss tense-aspectmood marking, with specific reference to complex verb forms in Swahili, before turning to comparative evidence from Rangi and siSwati in the following sections.

The typical Bantu verb form is comprised of several elements, not all of which are necessarily present in a given verb form but which always appear in a fixed order. A schematic verbal template for Swahili, following Meeussen (1967) and Schadeberg (1992), is given in (15).

The Swahili verbal template

\begin{tabular}{|l|l|l|l|l|l|l|l|l|l|}
\hline 1 & 2 & 3 & 4 & 5 & 6 & 7 & 8 & 9 & 10 \\
\hline $\begin{array}{l}\text { Pre- } \\
\text { initial } \\
\text { negative }\end{array}$ & SM & $\begin{array}{l}\text { Post- } \\
\text { initial } \\
\text { negative }\end{array}$ & Tense & Relative & Stem & OM & $\begin{array}{l}\text { Verbal } \\
\text { base }\end{array}$ & Final & $\begin{array}{l}\text { Post- } \\
\text { final }\end{array}$ \\
\hline
\end{tabular}

Swahili simple verbs comprise of a single verb form inflected for subject and tenseaspect information. For example, a present progressive event is marked by the prefix $n a-(16)$, and the past tense is marked by the prefix $l i-(17)$.

$$
\begin{array}{ll}
\text { Ni-na-end-a } & \text { shule- } n i \\
\text { SM1 SG-PRES.PROG-go-FV } & \text { 9.school-LOC } \\
\text { 'I am going to school' } &
\end{array}
$$

$$
\begin{array}{ll}
\text { Tu-li-pik-a } & \text { cha-kula } \\
\text { SM1PL-PAST-cook-FV } & \text { 7-food } \\
\text { 'We cooked food' } &
\end{array}
$$

Complex verbal constructions can be formed using the auxiliary verb -wa 'be'. The auxiliary is inflected for temporal information, typically with $l i$ - past, $n a$ - present or $t a$ - future. The main verb carries aspectual information, such as situative/participial ki- (18), progressive na- (19) or perfective me- (20) (cf. Ashton 1947: 247-263, Nurse 2008).

\footnotetext{
${ }^{9}$ We concentrate on complex verbal constructions with -wa 'be', which is the most central Swahili auxiliary form. Other verbs (such as -ja 'come' or -pata 'get') have restricted auxiliary usage, typically only with infinitival complements (cf. e.g. Ashton 1947: 273-277). The analysis of Rangi auxiliaries in the following section could be extended to cover these cases since, in Rangi, different auxiliary forms are used to encode subtly distinct meanings, albeit in restricted contexts.
} 
A-li-kuwa

SM1-PAST-be

'S/he was saying'
A-ta-kuwa

SM1-PAST-be

'S/he will be saying'

Wa-ta-kuwa

SM2-FUT-be

'They will have arrived' a-ki-sem-a

SM1-SITU-say-FV

a-na-sem-a

SM1-PROG-say-FV

wa-me-fik-a

SM2-PERF-arrive-FV

As the preceding examples show, in complex verb forms the auxiliary hosts temporal information while the main verb carries aspectual information, as well as providing lexical semantic information about the event. Since Swahili only allows one TAM marker per verb form, complex verbal constructions are an essential part of the TAM paradigm of the language, serving to express tense-aspect distinctions for which no single TAM marker is available, such as in the examples (18) to (20) above. The examples also show that both the auxiliary and the main verb exhibit subject agreement. Double subject marking is obligatory in complex verbal constructions in Swahili (that is, neither subject marker can be dropped), and both subject markers necessarily refer to the same referent. Also, no lexical material can intervene between auxiliary and main verb - any adverbial expressions follow the main verb (except for 'extra-clausal' interjections):

$$
\begin{array}{lcll}
\text { Wa-ta-kuwa } & \left({ }^{*} \text { mapema }\right) & \text { wa-me-fik-a } & \text { mapema } \\
\text { SM2-FUT-be } & \text { early } & \text { SM2-PERF-arrive-FV } & \text { early } \\
\text { 'They will have arrived early.' } & &
\end{array}
$$

In terms of Dynamic Syntax, the interpretation of the first subject marker (of the auxiliary) is fixed either through information from preceding lexical input, or from the context. The analysis of complex verbal constructions must now ensure that the interpretation of the second subject marker is fixed identically to the first one. At the same time, we want to retain a unified analysis of Swahili subject markers as underspecified with respect to their interpretation, and not introduce systematic lexical ambiguity into the analysis - distinguishing, for example, between subject markers with free interpretation and anaphoric ones with fixed interpretations used only in auxiliary constructions. Rather, the difference in the way the interpretation of the subject marker is established will fall out from the different contexts in which it is used.

Examples like (18) to (21) have in fact been used to argue that Bantu subject markers cannot be analysed as incorporated pronouns. This follows from the observation that the interpretation of the second subject marker is so restricted, and so have been seen as evidence for an analysis of Bantu subject markers as agreement markers, in which case both subject markers in, for example, (21) can be analysed as agreeing with the (overt or empty) subject of the whole complex verbal construction (cf. Buell 2005, Thwala 2006, Henderson 2007, Diercks 2010, Carstens 2011). The DS analysis of Bantu subject markers is affected by this criticism as it assumes that they are effectively interpreted like pronouns. In order to maintain this analysis, it is 
important to provide a principled analysis of the role of the subject markers in complex verbal constructions.

We will develop our analysis by taking the underspecified nature of the auxiliary verb as a starting point. Following Cann's $(2006,2007,2011)$ analysis of copula constructions, we will propose that the auxiliary lexically introduces a predicate metavariable which will be updated with information from the main verb once this has been parsed. This means that complex verbal constructions decorate only one semantic tree and are associated with a single predicate-argument structure. The tree is partly developed by information from the auxiliary verb, which provides the subject interpretation, the predicate frame and tense information. After parsing the auxiliary, the semantic tree is not yet complete since there is an outstanding requirement for a value for the metavariable introduced by $-w a$ 'be': A fully-specified formula decoration that would enable interpretation of the predicate node is still outstanding. The lexical verb then provides this information and enables update of the underspecified predicate annotation. The interpretation from the second subject marker decorates the same subject node already developed and annotated, and so the interpretation is necessarily identical. Aspectual information is also added to the temporal information already established, and a complete tree ensues.

In addition to the concepts of underspecification and update, the analysis also builds on the fact that in the DS system, tree nodes are uniquely identified with respect to each other (e.g. as argument daughter node of the root node) and so when the same node is 'built twice', the information will collapse and only decorate one node. We will see that this is relevant for the parsing of the second, lexical verb in complex verbal constructions. Here, the subject marker and the tense marker trigger the building of structure as in any other situation, but with respect to the same root node as the information from the auxiliary. This means that the same subject node and the same predicate-argument structure are built. Since the subject marker introduces a metavariable, its information can harmlessly combine with the information on the subject node already established. Since the established predicate node is decorated with a metavariable, no problem results if the same node is now 're-built' with information from the lexical predicate. Both cases are instances of local update and entirely normal in the system. However, we have to ensure that this rebuilding of structure only occurs in the context of complex verbal constructions involving underspecified auxiliaries - otherwise the system would be able to produce large amounts of inconsistent information (which of course would result in the termination of the relevant parse, but which would still lead to extensive overgeneration). This will be done by lexically requiring that, when the subject marker and the tense marker are parsed, any existing fixed tree structure present must contain a predicate variable.

To illustrate the analysis, we will now go through a relevant derivation of the example in (22) in more detail.

$\begin{array}{lcl}\text { Wa-talii } & \text { wa-ta-kuwa } & \text { wa-me-fik-a } \\ \text { 2-tourist } & \text { SM2-FUT-be } & \text { SM2-PERF-arrive-FV } \\ \text { 'The tourists will have arrived' } & \end{array}$

Clause-initial NPs in Bantu languages can be projected on a Link structure or an unfixed node (see Cann et al. 2005, Marten 2007, 2011, Gibson 2013). Although not much hinges on this for the overall argument, we will assume a Link analysis for the present derivation as this brings out more clearly the (putatively problematic) 'pronominal' use of subject markers. Once the Link structure is built and annotated 
with information from watalii 'tourists', the subject marker projects a locally unfixed node and decorates it with the underspecified formula value (Fo( $\left.\left.\mathbf{U}_{\mathrm{WA}}\right)\right)$. The TAM marker on the auxiliary introduces temporal information - in this case $t a$ - introducing Tns(FUT) - and licenses the building of a fixed subject node and a fixed predicate node. Like lexical verbs in Swahili, the lexical entry for -wa requires the presence of a predicate node as a trigger in the IF statement. The predicate node is then decorated by lexical actions from - wa 'be' with a predicate metavariable $\mathrm{Fo}(\mathbf{B E})$ and a requirement for the update with a full formula value (cf. Cann 2006, 2007, 2011):

$$
\begin{aligned}
& \text { Lexical entry for auxiliary }-(k u) w a \text { 'be' } \\
& \text { IF } \quad \text { ?Ty }(\mathrm{e} \rightarrow \mathrm{t}) \\
& \text {-(ku)wa THEN } \operatorname{put}(\operatorname{Fo}(\mathbf{B E}), ? \exists x . \operatorname{Fo}(\mathrm{x})), \operatorname{go}\left(<\uparrow_{1}>\right), \operatorname{go}\left(<\downarrow_{0}>\right) \\
& \text { ELSE abort }
\end{aligned}
$$

The lexical entry of - $w a$ is very similar to the lexical entries for intransitive verbs such as -fik- 'arrive' in (12) above. However, the formula value is a metavariable, and requires further input for its interpretation, which in our example will be provided by the main verb to be parsed later. Another difference is that we analyse the (erstwhile) final vowel $-a$ as part of the lexical entry for $-w a$ : Over the course of grammaticalisation, the final vowel has been reanalysed as part of the verbal root. This means that there is no bottom restriction which, as noted above, is introduced by the final vowel with all inflected lexical verbs. The bottom restriction prevents any further structure from being built from the node, but in the process of auxiliary grammaticalisation, the final vowel has lost its own lexical specifications, and so no bottom restriction is introduced. This means that further structure can be built from the predicate node: As we will see, the node decorated with $\mathrm{Fo}(\mathbf{B E})$ can be further developed once the main verb is parsed. However, while the introduction of the bottom restriction has been lost, other lexical actions of the final vowel - $a$ are retained. In particular, the pointer movement associated with final vowels has become part of the lexical actions of $-w a$. As noted above, the final vowel triggers pointer movement away from the predicate node, and the same pointer movement occurs with -wa, which we claim is a reflex of the lexical actions of the (now reanalysed) final vowel $-a$ in the auxiliary $-w a$. This means that the copula is not available for contextual update, for example in ellipsis contexts in Swahili, which is correct. ${ }^{10}$

All these differences are indicative of the grammaticalisation process resulting in auxiliaries, and we will see more of this lexical variation below. Finally, note that the lexical actions of - $w a$ do not provide a tense-aspect annotation of the root note, which has been provided by the preceding TAM marker. There is, however, variation also in this respect, and we will see in Rangi and siSwati that some auxiliaries - which we argue are less grammaticalised - do provide temporal and aspectual annotations.

Returning to the case at hand, apart from the differences discussed, the derivation continues in the same manner as with non-complex verbs and corresponds to the steps discussed in the previous section: Fixed structure is built, the fixed subject node provides a node with which the locally unfixed node can merge, and the pointer returns to the root node:

\footnotetext{
${ }^{10}$ The analysis we propose here is analogous to the analysis of expletive pronouns in Cann et al. (2005: 195), which similarly involves lexically induced pointer movement away from a node decorated with a metavariable. Ellipsis in Swahili, and Bantu more widely, remains to be studied in detail, but see e.g. Ngonyani (1998) for some examples of argument ellipsis with applicative verbs.
} 


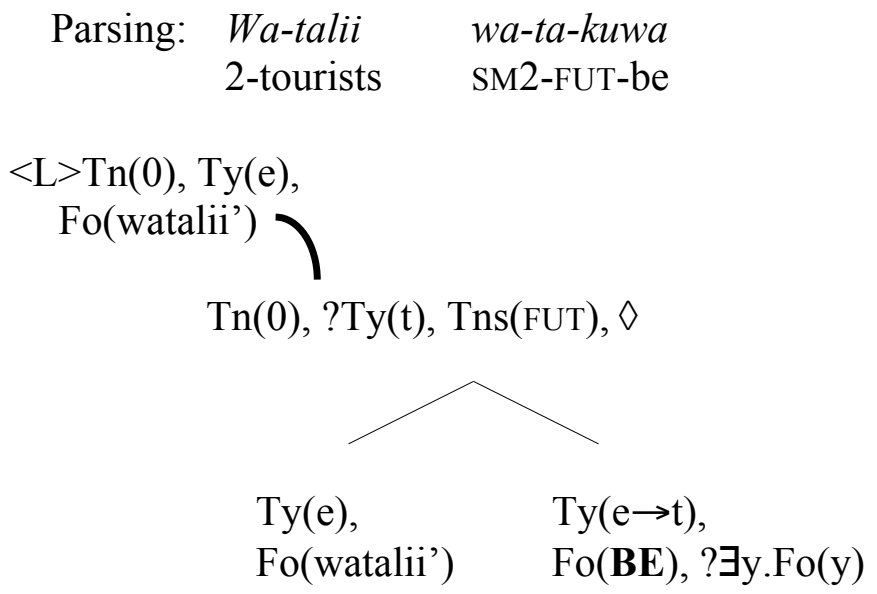

The difference between (24) and the parsing of a simple verbal structure is that in (24), at this stage in the parsing process, no predicate interpretation has been provided, and the predicate node is merely decorated with a placeholder $(\mathrm{Fo}(\mathbf{B E}))$, in need of further update. The overall tree is not complete, with the requirement ?Ty $(\mathrm{t})$ at the root node still outstanding.

At this point, the subject marker of the main verb is encountered. Given the lexical entry for subject markers presented in (6) above, the subject marker $w a$-cannot be parsed in this context: A requirement of the lexical entries for subject makers discussed so far is that no fixed structure has yet been built, yet in (24), there is both a fixed subject node, and a fixed predicate node. In order to model the use of subject markers in auxiliary constructions, we propose a slightly more complex lexical entry for subject markers, which distinguishes two different structural contexts in which subject markers can be used: In simplex verb forms, without any preceding structure, and in the context of auxiliary constructions, in which structure has already been established. However, with preceding auxiliaries, any existing structure will necessarily contain the predicate variable Fo(BE), and it is this which licenses the use of the subject marker in (24). The relevant lexical entry is provided in (25):

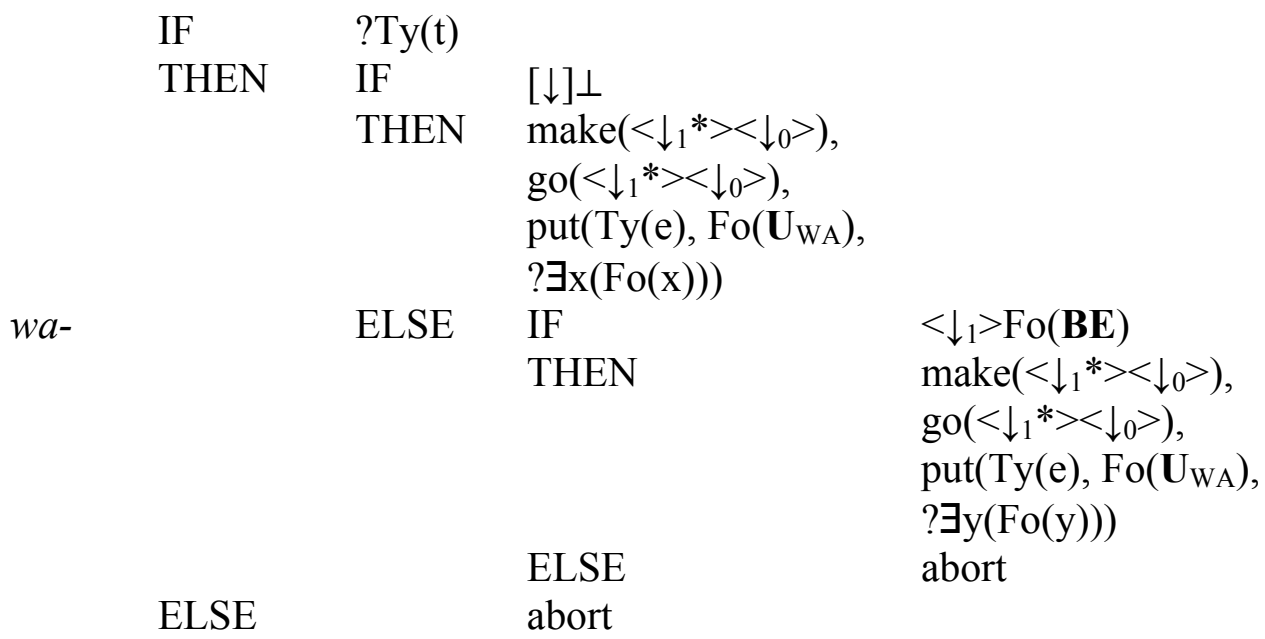

Given the lexical actions, the subject marker is projected onto a locally unfixed node - the only formal restriction on locally unfixed nodes is that only one at a time can be projected, and in this case, the earlier locally unfixed node has already been fixed. The locally unfixed node is unfixed with respect to the same (and only) root node of 
the derivation so far. Since a fixed subject node does in fact already exist, the locally unfixed node can collapse onto this node. Since the fixed subject node is decorated with a full formula value, the interpretation of the metavariable introduced by the (second) subject marker of the auxiliary must be compatible with the value that already holds at the subject node - whilst a node can be 're-annotated', inconsistent information would lead the derivation to fail. A consequence of this is that the two pronominal elements have to be interpreted as identical, since they decorate the very same tree node. This effect results purely from the specific context in which the subject marker of auxiliaries is parsed. At the same time, the lexical actions of the subject marker, and the formula value introduced, remain the same, thus maintaining a uniform, pronominal analysis of the subject marker. ${ }^{11}$

Next comes the aspect marker me-. We assume that this has a lexical entry similar to the past tense marker $l i$-, illustrated in the previous section. However, there are two differences between the two markers: Firstly, the TAM annotation at the root node resulting from me- is Asp(PERF) rather than Tns(PAST). Secondly, while li- can only be used as tense marker - either in simple verb forms or with auxiliaries - $m e$ - is an aspect marker which can be used in simple verb forms and in main verbs following an auxiliary. In DS terms this means that the building of predicate-argument structure is licensed not only in the absence of a fixed subject node (as was the case with $l i-$ ), but also in the presence of a fixed subject node, provided that there is also a fixed predicate node annotated with a predicate metavariable, similar to the conditions of subject markers illustrated in (25). This is expressed in the lexical entry for the prefect marker $m e$ - in (26).

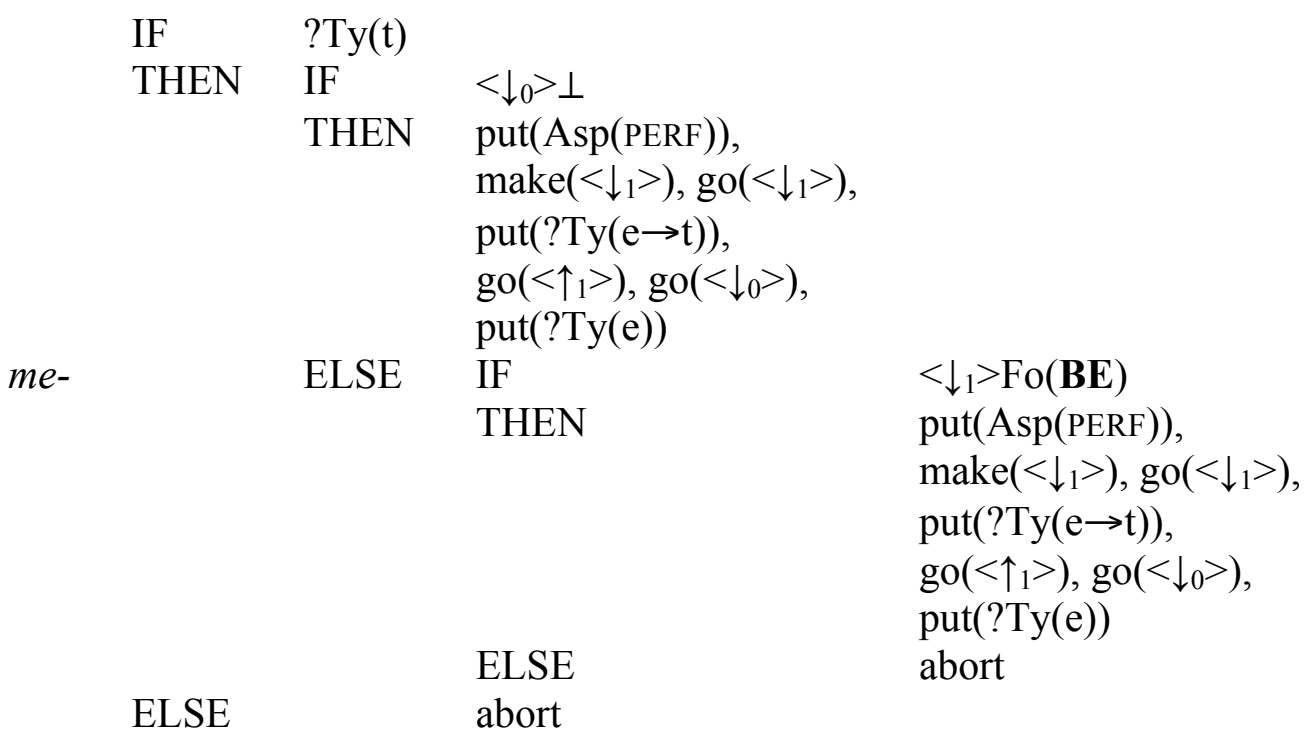

As in the lexical entry for subject makers in (25), the lexical entry in (26) distinguishes between two conditions (IF statements), one in which no fixed subject node is present when the lexical entry is run, and the second one in which there is a fixed subject node plus a predicate metavariable. These more complex conditions

\footnotetext{
${ }^{11}$ Having said this, there is no formal reason why the two sets of lexical actions in the THEN statements should be identical. The way we have formulated the lexical contribution of the subject marker allows for a scenario in which a different lexical contribution is made in each of the two different contexts - this may prove useful, for example, for the analysis of the grammaticalisation of agreement. On the other hand, what is important here is that an analysis of subject markers as uniformly pronominal is perfectly possible from our dynamic perspective.
} 
ensure that tensed verb forms project their own semantic tree structure, and can only be used in the absence of existing fixed structure. However, the exception to this rule is that in such instances when the existing structure contains a predicate metavariable - i.e. which has been projected by an auxiliary - the building of predicate-argument structure is licensed. In this case, the 'new' structure will merely 're-build' the existing one, albeit with a new, updated combination of tense and aspect information. $^{12}$

Finally, when the main lexical verb is parsed, it introduces predicate semantics, decorates the predicate node and enables update of the metavariable. The interpretation of the subject node thus comes from the interpretation of the two subject markers, while the eventual interpretation of the predicate is provided by information from the main verb. Crucially however, at the end of the derivation, all the information is compiled into one single semantic structure:

$$
\begin{aligned}
& \text { Parsing: Wa-talii wa-ta-kuwa } \\
& \text { 2-tourists SM2-FUT-be } \\
& \text { wa-me-fik-a } \\
& \langle L\rangle \operatorname{Tn}(0), \operatorname{Ty}(\mathrm{e}), \\
& \text { Fo(watalii') } \\
& \operatorname{Tn}(0), \operatorname{Ty}(\mathrm{t}), \operatorname{Tns}(\mathrm{FUT}), \operatorname{Asp}(\mathrm{PERF}), \diamond \\
& \text { Ty(e), } \quad \text { Ty }(e \rightarrow t), \\
& \text { Fo(watalii') Fo(fik') }
\end{aligned}
$$

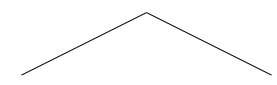$$
\text { SM2-PERF-arrive-FV }
$$

Our analysis of Swahili complex verbal constructions thus critically involves notions of underspecification and update, and allows the 're-building' of semantic structure, albeit restricted to cases in which the structure which has already been established contains a predicate variable. This allows us to maintain a pronoun-like characterisation of the subject marker (which can be interpreted from the context without the assumption of an additional empty pronominal element such as 'pro') while at the same time ensuring that in complex verbal expressions the subject marker of the main verb necessarily receives the same interpretation as the subject marker of the auxiliary.

Overall, the analysis assumes that in complex verbal constructions, a single semantic structure is built and annotated from information provided by both parts of the construction: While the auxiliary provides the subject interpretation and an underspecified predicate-argument structure, the main verb merely provides an underspecified subject metavariable, which can be updated by existing information when merging with the fixed subject node, but provides the update of the predicate interpretation. The resulting form has a single predicate-argument structure, annotated with complex temporal-aspectual interpretation. In the following sections, we will extend the empirical scope of the discussion by looking at the related Bantu languages Rangi and siSwati, which have a much richer inventory of auxiliaries than Swahili.

\footnotetext{
${ }^{12}$ As in the case of subject markers, the lexical entry allows for the possibility to lexically encode two different sets of actions in the two different contexts, for example to model different tense-aspect contributions in simple and complex verbal constructions, as is arguably the case for the 'situative' marker $k i$.
} 


\section{Rangi complex verbal constructions}

The Tanzanian Bantu language Rangi also uses a combination of simple and complex verb forms to encode tense-aspect distinctions. However, in contrast to Swahili, Rangi employs not only TAM prefixes, but also TAM suffixes: In simple verb forms, tense and aspect are indicated through a combination of markers appearing in the preverbal and post-verbal position, corresponding to slot 4 and slot 9 in the template in (15). This can be seen below where in example (28) the present progressive is indicated through the presence of the prefix iyó- and the suffix $-a$, whilst in example (29) recent past tense is marked by the prefix $a$ - and perfective aspect is marked by the suffix -iré. ${ }^{13}$

$$
\begin{array}{lll}
\text { I-bula } & \text { r-íyó-nyúúnt- } a & \text { vya-liih- } a \\
\text { 5-frog } & \text { SM5-PROG-jump-FV } & \text { SM8-be.far-FV }
\end{array}
$$

'The frog is jumping high/far'

$$
\begin{array}{lll}
\text { Nünż } & n \text {-á-wúr-iré } & \text { ma-taanga } \\
\text { 1SG. PP } & \text { SM1SG-PAST1-buy-PERF } & \text { 6-pumpkin } \\
\text { 'I bought a pumpkin' } &
\end{array}
$$

In complex verbal constructions, Rangi uses different auxiliaries to encode different tenses. This contrasts with Swahili in which the auxiliary -wa 'be' is used across different tenses, but with distinct tense-marking prefixes in each instance. For example, in Rangi, the auxiliary $-r i$ is used in the formation of the recent past (30) whilst the auxiliary -ija is used to encode distant past (31).

$\begin{array}{llll}N \text {-áá-ri } & n \text {-a-téy-iré } & \text { mu-teho } & \text { w-ááni } \\ \text { SM1SG-PAST1- } & \text { SM1SG-PAST1-set-PERF } & \text { 3-trap } & \text { 3-my } \\ \text { AUX } & & \\ \text { 'I have set my traps' } & \end{array}$

$\begin{array}{lll}\text { Mama } & a \text {-íja } & \text { a-dóm-iré } \\ \text { 1a.mother } & \text { SM1a-AUX.PAST2 } & \text { SM1a.PAST2-go-PERF } \\ \text { 'Mother has gone' } & \end{array}$

As can be seen in the examples above, double subject marking is obligatory in the present tense and the distant past tense which are formed using -rit and -ija respectively. Thus, in example (30), first person singular subject agreement $n$ - is triggered on both the auxiliary náári and on the main verb natéyiré. Similarly, in example (31) class 1a subject agreement in the form of $a$-is triggered on both the auxiliary and on the main verb, showing agreement with the subject expression mama 'mother'. 14

\footnotetext{
${ }^{13}$ Rangi is a two-tone language. Surface high tones are marked by an acute accent whilst surface low tones are unmarked.

${ }^{14}$ Rangi also exhibits a typologically and comparatively unusual constituent order in which the auxiliary appears post-verbally. This is restricted to declarative main clauses in the immediately and general future tenses. Whilst an in-depth discussion of this non-canonical constituent order is beyond the scope of the current paper, the analysis presented here is consistent with that developed for this verb-auxiliary ordering in Gibson (2013) which crucially also employs the concepts of underspecification and update and in which the structure built by auxiliaries combines with that introduced by lexical main verbs.
} 
We make similar assumptions for Rangi clause structure as were presented in section 2 for Swahili. The obligatory subject marker is projected onto a locally unfixed node as the result of the lexical actions encoded in the subject marker. An overt subject expression (when present) is projected onto a Link structure. Parsing a tense-aspect marker results in the introduction of the appropriate tense-aspect information into the clause - represented by an annotation at the root node (such as Tns(PAST)). Parsing a tense-aspect marker also results in the projection of a fixed subject node and a fixed predicate node, reflecting the historical origins of tenseaspect markers as verbs. The verb stem similarly builds a fixed predicate-argument frame, with the extent of the structure determined by the valency of the verb. The verb stem also crucially makes a lexico-semantic contribution to the clause which is represented by the annotation on the predicate node (e.g. Fo(dom')).

Like in Swahili, the analysis of Rangi complex verbal constructions hinges on the concepts of underspecification and update. Building on the analysis of Swahili auxiliaries developed in the previous section, we analyse the auxiliaries in Rangi as responsible for the introduction of a predicate metavariable. This acts as a placeholder for the predicate information and is crucially in need of update before the parse is complete. The stages involved in parsing a Rangi complex verbal construction are shown below, with reference to an utterance formed with the auxiliary - $r \dot{t}$ such as shown in (32) (repeated from (30) above):

$$
\begin{array}{llll}
N \text {-áá-rí } & n \text {-a-téy-iré } & \begin{array}{l}
\text { mt-teho } \\
\text { SM1SG-PAST1-AUX }
\end{array} & \text { SM1SG-PAST1-set-PERF } \\
\text { 'I have set my traps } & & \text { 3-trap } & \text { 3-my }
\end{array}
$$

Parsing the subject marker on the auxiliary results in the projection of a locally unfixed node. The interpretation of the locally unfixed node is restricted to first person singular referents (as encoded by $n$-), and can be updated by a full formula value that refers to the speaker, in this case for example, 'John'. Parsing the past tense marker $a ́ a$ - licenses the projection of temporal information - here indicated by the annotation Tns(PAST) at the root node - as well as the projection of a fixed subject node and a fixed predicate node. The introduction of the fixed subject node enables the fixing of the locally unfixed node. Next, when the auxiliary -ri is parsed, the predicate node is annotated with a predicate metavariable $\mathrm{Fo}(\mathbf{B E})$ and the requirement that this be updated to a fully specified formula value before the parse is complete represented by ? $\exists x . F o(x)$ :

$$
\begin{aligned}
& \text { Parsing: } N \text {-áá-rí } \ldots \\
& \operatorname{Tn}(0), ? \operatorname{Ty}(\mathrm{t}), \operatorname{Tns}(\mathrm{PAST}) \\
& \begin{array}{ll}
\text { Ty(e), } & \text { Ty(e } \rightarrow \text { t), } \\
\text { Fo(John'), } \diamond & \text { Fo(BE), ? } \exists x . F o(x)
\end{array}
\end{aligned}
$$

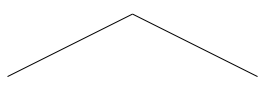

The rest of the derivation continues as was shown for Swahili above with the information hosted by the main verb resulting in the projection of structure resulting from the combination of computational rules and lexical actions. 
Similar steps are involved in parsing constructions formed using the auxiliary -ija. However, the difference between $-r \dot{i}$ and -ija is that $-r \dot{i}$ makes no temporal contribution to the clause and instead is dependent upon the inflectional tense marking (such as áá- in the example above). Like the Swahili auxiliary $-w a,-r \dot{t}$ in Rangi simply builds a fixed subject node and a fixed predicate node annotated with a metavariable placeholder and in an example such as (32) above, does not introduce any specific tense-aspect information. In contrast, -ija lexically introduces distant past tense temporal information. We propose therefore that the auxiliary -ri is more grammaticalised than -ija, with the later having retained more lexical-semantic content. ${ }^{15}$ However, despite this difference in the construction of the recent past and the distant past forms, similar assumptions hold about structure building, the combination of the temporal and aspectual information across the different forms, and the establishment of propositional structure. The steps involved in parsing a construction formed with the auxiliary $-i j a$, such as that shown in (34), are outlined below.

$\begin{array}{lll}\text { Mama } & a-i ́ j a & a \text {-dóm-iré } \\ \text { la.mother } & \text { SMla-AUX.PAST2 } & \text { SMla.PAST2-go-PERF } \\ \text { 'Mother has gone' } & \end{array}$

In such an utterance, the overt subject expression mama 'mother' is projected onto a Link structure. This expression provides the background against which the subject marker $a$ - on the auxiliary can be interpreted. Parsing the auxiliary -ija results in the projection of a fixed subject node and a fixed predicate node, as was seen in previous cases. Parsing -ija also results in the introduction of the associated temporal information - in this case distant past (Tns(DISTANT PAST)). These steps can be seen in the lexical entry for -ija shown in (35) whilst the resulting partial tree is shown in (36). It is worth noting that the lexical entry for the Rangi auxiliary -ija is effectively the same as the entry for the Swahili past tense marker $l i$ - except that - $i j a$ introduces the metavariable $\mathrm{Fo}(\mathbf{B E})$ on the predicate node, whereas $l i-$, which must occur with a verb form, does not introduce such a metavariable. The entry for -ija differs also from that for Swahili verbs, as well as from Rangi main verbs and the Rangi auxiliary $-r i$ in that the IF clause indicates that the trigger is a ?Ty $(\mathrm{t})$ node rather than a ? Ty $(\mathrm{e} \rightarrow \mathrm{t})$ node. This means that -ija can be parsed when the pointer is at the root node, while lexical verbs and the auxiliary $-r \dot{t}$ require the presence of a predicate node, typically constructed from lexical information of a preceding TAM marker. The difference in lexical triggers for verbs is just one parameter in the complex grammaticalisation process of verbs, auxiliaries and TAM markers.

$$
\begin{aligned}
& \text { Lexical entry for the distant past auxiliary -ija } \\
& \text { IF } \quad \text { Thy }(\mathrm{t}),<\downarrow_{1} *><\downarrow_{0}>\text { Ty(e) } \\
& \text {-ija THEN put(DISTANT PAST)), make }\left(<\downarrow_{0}>\right), \operatorname{go}\left(<\downarrow_{0}>\right) \text {, put(?Ty(e)), } \\
& \operatorname{go}(<\uparrow 0>) \text {, make }\left(<\downarrow_{1}>\right) \text {, go }\left(<\downarrow_{1}>\right) \text {, put }(\text { Ty }(\mathrm{e} \rightarrow \mathrm{t}) \text {, } \\
& \text { Fo(BE), ? } \exists x . F o(x)) \\
& \text { ELSE abort }
\end{aligned}
$$

\footnotetext{
${ }^{15}$ This will be shown to be similar to the situation in siSwati where we claim that different auxiliaries reflect different stages of grammaticalisation, and typically make a greater lexical-semantic contribution to the clause than -wa in Swahili and -ri in Rangi.
} 
$<\mathrm{L}>\operatorname{Tn}(0), \operatorname{Ty}(\mathrm{e})$,

Fo(mama')

$\operatorname{Tn}(0)$, ?Ty(t), Tns(DISTANT PAST), $\diamond$

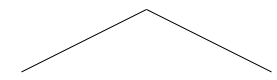

$\operatorname{Ty}(\mathrm{e}), \quad \operatorname{Ty}(\mathrm{e} \rightarrow \mathrm{t})$,

Fo(mama') $\quad$ Fo(BE), ? Эy.Fo(y)

As the subsequent parts of the utterance are parsed, the derivation continues. Parsing the subject marker $a$ - on the main verb results in the projection of a locally unfixed node. This node collapses onto the fixed subject node already present in the tree - this is possible since the class 1 subject marker $a$-is compatible with the class 1 nominal expression mama 'mother'. Not only is this collapse possible in the current derivation, it is necessary. Again, as was seen for Swahili, this building and re-building of the structure guarantees the co-reference of the subject markers, with each variable decorating the same node. Similarly, the collapsing of the structure introduced by the auxiliary and the main verb results in them referring to a single semantic event. Parsing the suffix -iré on the main verb results in the introduction of the perfective aspect (here represented by the annotation Asp(PERF) at the root node). This differs from Swahili which only has the pre-stem position (slot 4) available for a morphological tense-aspect marker, therefore necessitating the presence of an auxiliary to host the temporal information (in an instance in which the main verb hosts aspect). Yet in both languages, the use of the auxiliary forms can be seen to be motivated by the necessity to encode specific tense-aspect combinations which are not possible over a single form, despite the availability of two tense-aspect slots in Rangi (see Gibson 2013). Since no additional morphological material can appear after the perfective suffix, parsing -iré also indicates that no further structure can be built. In this case, the parse is complete and the information is compiled up the tree and all outstanding requirements are resolved.

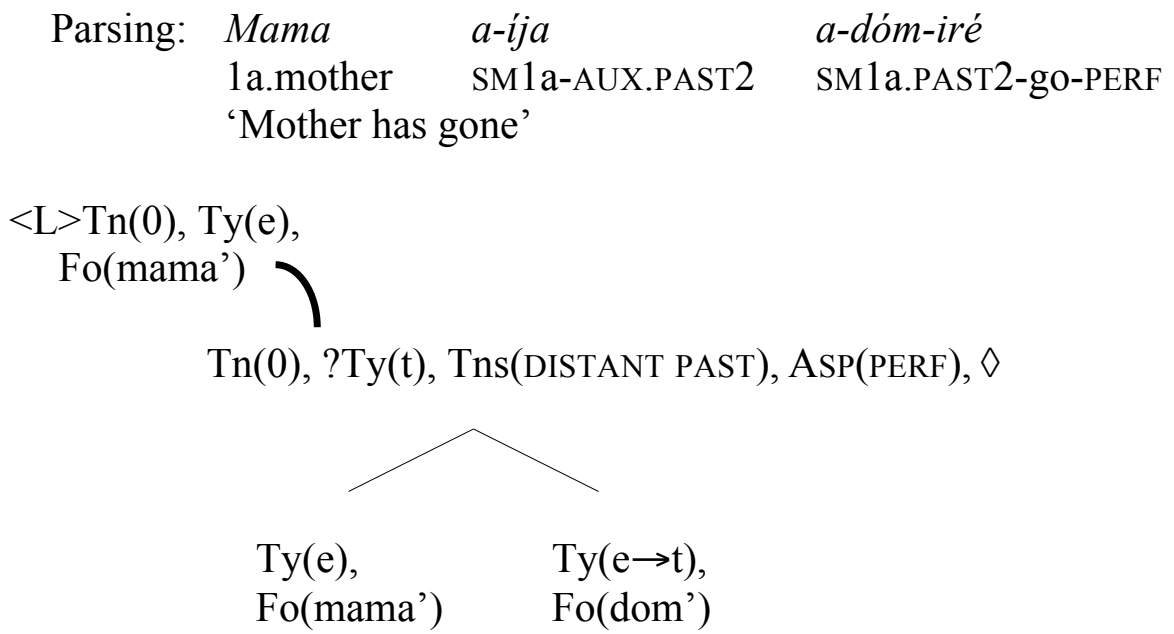


Crucially, in these highly restricted conditions, the same structure can be built twice but is mapped onto a single tree. Whilst the analysis for the Swahili auxiliary -wa can be extended to $-r \dot{t}$, this is not the case for -ija which carries greater lexical-semantic content and introduces temporal information. However, a uniform analysis based on the notions of underspecification and update can be maintained, with -ija introducing a predicate metavariable as well as the temporal contribution, and this is taken to indicate a different point in the grammaticalisation process.

The next section will examine complex verbal constructions in siSwati, showing the way in which these constructions differ from those found in Swahili and in Rangi, whilst arguing that a uniform analysis can still be maintained.

\section{5. siSwati complex verbal constructions}

Complex verbal constructions are also found in Bantu languages spoken in Southern Africa. However, the details of the system in siSwati (and related Southern Bantu languages $)^{16}$ differ considerably from Swahili and Rangi in terms of the inventory of auxiliaries and the restrictions on complex verbal constructions. siSwati has auxiliary constructions based on the copula -be 'be' and the form -se which is used only in complex constructions. However, in contrast to Swahili and Rangi, siSwati also has a large number of verbs - about 30 - which can be used as auxiliaries, and which in this usage assume more abstract, adverbial meanings relating to temporal, aspectual, or modal distinctions. A wide range of differences between the auxiliaries and verbs with respect to their morphology, meaning and complementation has been observed (Rycroft 1981, Taljaard et al. 1991, Ziervogel and Mabuza 1976). We suggest below that many of the auxiliary forms, and the variation among them, are the result of grammaticalisation processes in which the lexical contribution of the auxiliaries - e.g. as providing merely root node annotations, partial predicate-argument structure and/or a predicate variable - has changed over time. Furthermore, up to three auxiliaries can be used in a verbal construction, whereas Swahili and Rangi exploy maximally one auxiliary form in a given construction. We show, however, that the analysis presented for Swahili and Rangi above can be extended to the multiple auxiliary constructions found in siSwati, with structure building, the enrichment of underspecified content and the combining of sematic values (including tense, aspect and mood) taking place in much the same way.

The first auxiliary construction we will discuss here is based on the auxiliary verb stem -be, which historically is the stative perfect form of the copula - $b a$ (Taljaard et al. 1991: 144). In complex verbal constructions -be is followed by the main verb in the so-called 'situative' form and can take a variety of tense inflections:

$$
\begin{array}{ll}
\text { Ngi-be } & \text { ngi-bon- } a \\
\text { SM1 SG-be } & \text { SM1SG-see-FV } \\
\text { 'I was seeing' (Taljaard et al. 1991: 144) }
\end{array}
$$

\footnotetext{
${ }^{16}$ The auxiliary system and related complex verbal constructions described here for siSwati are found in a similar way in related Nguni languages such as Zulu, Xhosa or Ndebele as well as in Sotho-Tswana languages such as Tswana. Auxiliaries are sometimes called 'deficient verbs' in the literature on Southern Bantu languages, and the details of the system differ from language to language. See, for example, Doke (1992: 202-214) or Zeller (2006) for Zulu, Du Plessis and Visser (1992: 246-277) for Xhosa, Cole (1955: 191, 236, 286) for Tswana.
} 


$$
\begin{array}{ll}
\text { Ngi-ta-be } & \text { ngi-tawu-nats- } a \\
\text { SM1SG-FUT-be } & \text { SM1SG-FUT-drink-FV } \\
\text { 'I shall be about to drink' (Nichols 2011: 58) }
\end{array}
$$

Both the auxiliary and the main verb can carry a subject marker, and both subject markers necessarily refer to the same referent. However, if the auxiliary is uninflected for tense, the subject marker of the auxiliary is commonly dropped and the auxiliary cliticises to the main verb:

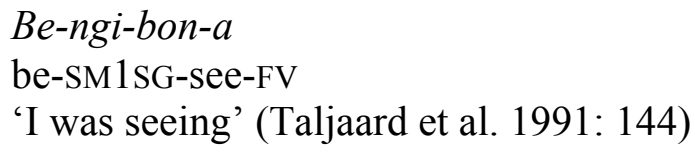

On the other hand, when -be is used with a past tense concord (41), it is -be itself which tends to get omitted, resulting in a form with two consecutive subject markers (41b):

$$
\begin{array}{ll}
\text { a. } & \text { Nga-be } \quad \text { ngi-nats-a } \\
& \text { SM1 SG.PAST-be SM1 SG-drink-FV } \\
\text { 'I was drinking' (Taljaard et al. 1991: 146) } \\
\text { b. }
\end{array}
$$

However, with other inflections, for example with the future tense, both subject markers are retained as in (39) above.

A second auxiliary construction is based on the aspectual formative -se, analysed here as an alterative aspectual marker following Nichols (2011). The alterative marker indicates a new event or state, which is different from a preceding one. The form is used only in complex verbal constructions, and might be historically related to the verb -sa 'dawn' (see Nichols 2011: 105/6, Nurse 2008: 161 for discussion):

$$
\begin{array}{ll}
\text { Nga-se } & \text { ngi-ya-hamb-a } \\
\text { SM1SG.PAST-ALT } & \text { SM1SG-DT-go-FV } \\
\text { '... and then I went away' (Taljaard et al. 1991: 150) }
\end{array}
$$

In many contexts, -se has lost its verbal function and is only found as an aspectual pre-verbal clitic:

$$
\begin{array}{llll}
\text { Se-ngi-fun- } a & \text { imali } & y a-m i & (<* \text { ngi-se ngi-fun-a }) \\
\text { ALT-SM1SG-want-FV } & \text { 9.money } & \text { 9-POSS.1SG } \\
\text { 'I now want my money' (Taljaard et al. 1991: 149) }
\end{array}
$$

In constructions like (43), the auxiliary cannot take a subject marker, even though a form with a subject marker can be reconstructed historically (as we do in brackets after the example).

In addition to auxiliary constructions with -be and -se, siSwati has a rich array of complex verbal constructions based on a range of auxiliaries often with quite specific or figurative meaning. There is considerable variation between the forms. Some have 
both main verb and auxiliary uses, others are just used as an auxiliary, some can be inflected like main verbs, others are uninflected or take special inflection (often an -e suffix), some always take a subject marker, others only take a subject marker in certain contexts, and yet others cannot take a subject marker at all. At the one end of the spectrum are main verbs used as auxiliaries, while at the other end of the spectrum are uninflected, invariant forms with only a historical relation to a possible verbal origin. Furthermore, different auxiliaries impose different restrictions on the inflectional form of the main verb, allowing or requiring infinitive, subjunctive, or participial main verbs. In terms of semantics, auxiliaries typically express aspectual, temporal or modal meaning.

The examples in (44) provide an illustration of siSwati auxiliaries, based on Ziervogel and Mabuza (1976: 116-125, 150-161) and Taljaard et al. (1991: 154-157). If there is a corresponding lexical verb form, this is given in brackets. The auxiliaries are arranged semantically, according to four groupings: Aspectual semantics (including aktionsart and adverbial meanings), temporal semantics, modal semantics, and conditional semantics (including conjunctions). The semantic categorisation is for illustrative purposes and does not reflect a more detailed or formal analysis. Yet it provides a good overview of the semantic range expressed by the forms, and often gives an idea about the metaphorical relation between auxiliary and corresponding main verb.

(44) Examples of siSwati auxiliaries

a. Aspectual semantics

-buye 'again, eventually' (< -buya 'return')

-cishe 'nearly, almost'

-etfuka 'suddenly' (<-etfuka 'get a fright')

-hambe 'all the time, often' (<-hamba 'go, travel')

-hlala 'keep on doing, continuously' ( $<$-hlahla 'sit')

-hle 'frequently'

-phindze 'again' (<-phindza 'repeat')

-phose 'almost' (<-phonsa 'throw')

-sa 'keep on doing, continually' (<-sa 'dawn')

-sheshe 'quickly' (<-shesha 'hurry')

-solo 'continue to'

-ye 'usually'

b. Temporal semantics

-cale 'first, initially' (<-cala 'begin')

-dzi 'until'

-fika 'immediately after' (<-fika 'arrive')

-kadze 'continuing in the past' $(<-$ kadze 'long ago')

-ke, -se 'once', neg. -ngeke 'never'

-khatsi 'just, only now' (< sikhatsi 'time')

-phange 'soon' (<-phanga 'do hastily, be greedy')

-suka, -esuka 'thereupon' (<-(e)suka 'leave')

-te 'until' (<-ta 'come') 


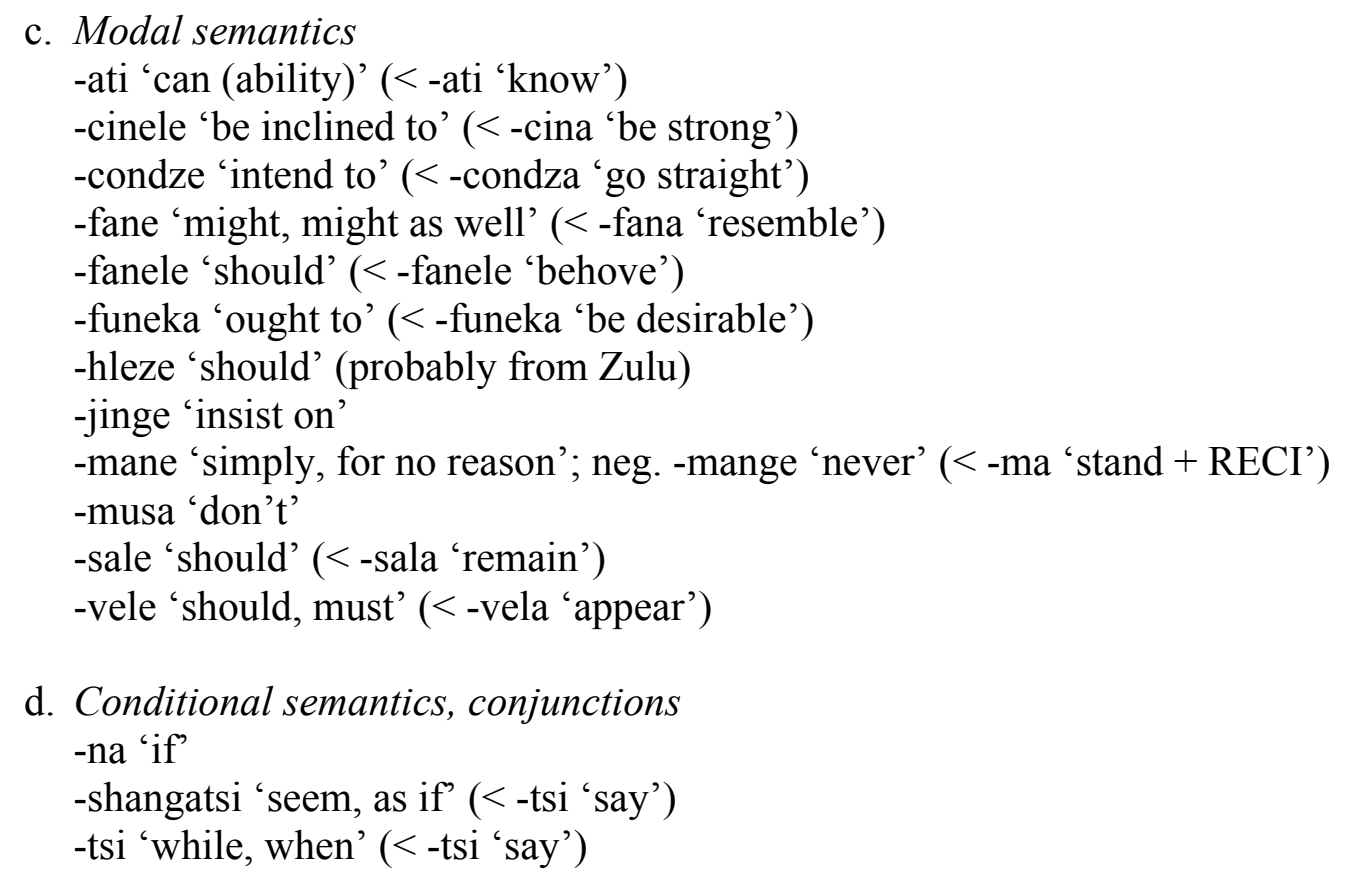

Typical auxiliary constructions consist of an auxiliary followed by the main verb in the infinitive (45), subjunctive (46), or indicative form ((47), (48)). Both verb forms have a subject marker, although with many forms, the subject marker of the auxiliary can be omitted ((47b), (48)):

$$
\begin{array}{lll}
\text { Leli-hhashi } & \text { la-phose } & \text { ku-ngi-wis-a } \\
\text { DEM5-5.horse } & \text { SM5.PAST-almost } & \text { INF-OM1SG-throw-FV } \\
\text { 'This horse nearly threw me' (Ziervogel and Mabuza 1976: 151) }
\end{array}
$$

(46) Ngi-phindze ngi-m-fun-e

SM1SG-repeat SM1SG-OM1-look.for-SBV

'I look for him again' (Ziervogel and Mabuza 1976: 116)

$$
\begin{aligned}
& \text { a. Li-shangatsi li-ya-f-a } \\
& \text { SM5-seem SM5-DT-die-FV } \\
& \text { 'It seems to be dying' (Ziervogel and Mabuza 1976: 116) }
\end{aligned}
$$

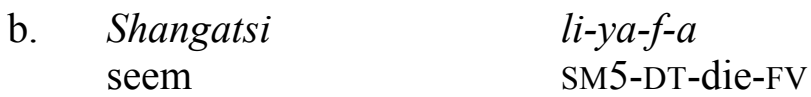

$$
\begin{aligned}
& \text { 'It seems to be dying' (Ziervogel and Mabuza 1976: 116) } \\
& \text { (48) (Wa-)cishe wa-luny-w-a yi-nyoka } \\
& \text { SM1.PAST-almost SM1.PAST-bite-PASS-FV COP9-snake } \\
& \text { 'He was almost bitten by a snake' (Nichols 2011: 52) }
\end{aligned}
$$

With some predicates, the auxiliary and the main verb agree in TAM form. For example, -buya 'return, again' in the indicative form is followed by the main verb in the indicative (49), while the subjunctive form -buye is followed by a subjunctive form (50). In both cases, the subject markers of the auxiliary can be dropped: 
(U-)buy-a u-ya-dzinw-a

SM1-return-FV SM1-DT-become.tired-FV

'He becomes tired again' (Ziervogel and Mabuza 1976: 118)
(A-) buy-e
a-dzinw-e
SM1.SBV-return-SBV
SM1.SBV-become.tired-SBV
'He becomes tired again' (Ziervogel and Mabuza 1976: 118)

Some auxiliaries take a default subject marker $\mathrm{ku}$ - (historically a locative subject marker), either optionally or as the only possibility:

$$
\begin{aligned}
& \text { Ku-fanele } \quad a-b a-b u t-e \\
& \text { SM17-behove SM1.SBV-OM2-ask-SBV } \\
& \text { 'He should ask them' (Ziervogel and Mabuza 1976: 118) }
\end{aligned}
$$

Finally, more than one auxiliary can be used in a single, complex verb form. This can be seen in example (52) below which employs both -ngahle 'might' and -phidze 'repeat' as auxiliaries:

$$
\begin{array}{lcccc}
\text { Ba-fana ba-phidze } & \text { ba-ngahle } & \text { ba-bheme } & \text { isangu } \\
\text { 2-boys } & \text { SM2-might } & \text { SM2-repeat } & \text { SM2-smoke } & \text { 9.pot } \\
\text { 'The boys might smoke pot again' (Thwala 2006: 357) } &
\end{array}
$$

In sum, the system of siSwati complex verbal constructions, and the number and kind of auxiliaries are different from the situation in Swahili and Rangi. There are considerably more auxiliaries, expressing a wide range of meanings, as well as variation in terms of morphology and syntax.

While a comprehensive analysis of siSwati complex verbal constructions and the underlying semantics of the system lies outside the scope of the present paper, we will show how the DS analysis developed in the preceding sections can shed light on some aspects of the morphosyntactic variation found in siSwati complex verbal constructions. In particular, we assume that the system overall is the result of complex grammaticalisation processes, and that (different uses of) individual auxiliaries reflect different stages of grammaticalisation. We further assume that grammaticalisation is essentially a lexical process and we will show how different grammaticalisation stages result from subtle variations in lexical specifications.

As a methodological and diachronic starting point, we assume fully specified lexical entries for verbs, providing both full lexical semantic content (i.e. formula values), as well as predicate-argument structure. The lexical entry in (53) shows this for the verb -funa 'want', taking a clausal complement.

$$
\begin{array}{ll}
\text { IF } & ? \operatorname{Ty}(\mathrm{t}),<\downarrow_{1} *><\downarrow_{0}>\operatorname{Ty}(\mathrm{e}) \\
\text { THEN } & \operatorname{make}\left(<\downarrow_{0}>\right), \operatorname{go}\left(<\downarrow_{0}>\right), \operatorname{put}(? \operatorname{Ty}(\mathrm{e})), \operatorname{go}(<\uparrow>), \\
& \operatorname{make}\left(<\downarrow_{1}>\right), \operatorname{go}\left(<\downarrow_{1}>\right), \operatorname{put}(? \operatorname{Ty}(\mathrm{e} \rightarrow \mathrm{t})), \operatorname{make}\left(<\downarrow_{1}>\right), \\
& \operatorname{go}\left(<\downarrow_{1}>\right), \operatorname{put}(? \operatorname{Ty}(\mathrm{t} \rightarrow(\mathrm{e} \rightarrow \mathrm{t})), \operatorname{Fo}(\operatorname{fun})), \operatorname{go}(<\uparrow>), \\
& \operatorname{make}\left(<\downarrow_{0}>\right), \operatorname{go}\left(<\downarrow_{0}>\right), \operatorname{put}(? \operatorname{Ty}(\mathrm{t})) \\
& \text { abort }
\end{array}
$$

For the verb to be parsed the pointer needs to be at the root node (with ?Ty(t)) and a locally unfixed node needs to be present. This ensures that the verb comes after the 
subject marker. This is indicated in the IF statement of the lexical entry. The verb then introduces the lexical semantic information to the clause and builds complex structure to allow for a transitive predicate, and an object node. The object node is decorated with the requirement for ?Ty(t) (in the final clause of the THEN statement) to ensure a clausal complement follows.

In the case of verbs like -funa 'want' which take a clausal or infinitival complement the distinction between main verb usage and auxiliary usage is blurred since a following infinitival verb could be a true complement, decorating a separate, embedded Ty(t) tree (as lexically required in (53)), or could provide an update of the skeletal predicate-argument structure of the auxiliary.

An illustrative lexical entry for an auxiliary is provided for -hlahla in (54). Whilst as a lexical verb -hlahla means 'sit', in its auxiliary usage modeled here it encodes continuous aspect. The entry is effectively the same as the entry for the Rangi auxiliary -ija in (35) above, showing the parallelism between the two languages in this respect:

$$
\begin{array}{lll} 
& \text { IF } & ? \operatorname{Ty}(\mathrm{t}),<\downarrow_{1} *><\downarrow_{0}>\operatorname{Ty}(\mathrm{e}) \\
\text { THEN } & \operatorname{put}(\operatorname{Asp}(\operatorname{CONT})), \operatorname{make}\left(<\downarrow_{0}>\right), \operatorname{go}\left(<\downarrow_{0}>\right), \operatorname{put}(? \operatorname{Ty}(\mathrm{e})), \\
& & \operatorname{go}(<\uparrow>), \operatorname{make}\left(<\downarrow_{1}>\right), \operatorname{go}\left(<\downarrow_{1}>\right), \operatorname{put}(\operatorname{Ty}(\mathrm{e} \rightarrow \mathrm{t})), \\
& \operatorname{Fo}(\mathbf{B E}), ? \exists \mathrm{xFo}(\mathrm{x}))) \\
& \text { ELSE } \quad \text { abort }
\end{array}
$$

The entry reflects auxiliary use, and no main verb use is possible, since the predicate metavariable $\mathrm{Fo}(\mathbf{B E})$ needs to be updated by a subsequent main verb which provides the formula value. In terms of semantic contribution, the auxiliary only provides a $\operatorname{Ty}(\mathrm{t})$ annotation, in this case aspectual information. However, since predicateargument structure, aspectual and, if applicable, temporal information (which may be provided by relevant inflection) are provided, infinitival main verbs are possible at this stage. The requirement for the presence of a locally unfixed node included in the IF clause means that the auxiliary requires the presence of a subject marker, just like a lexical verb in siSwati (as seen in (53)).

From this stage, several further developments are possible. The lexical information of the auxiliary may retain the requirement for a locally unfixed node in the IF clause, but no longer provide any structure. In this case, the THEN clause simply contains the instruction to annotate the root node with proposition-level information (aspectual, temporal, modal etc.), but no 'make' statements licensing structure building. Subject and predicate nodes are not built, and no predicate metavariable is supplied. The pointer simply remains at the root node and the building of predicate-argument structure is left until the inflected main verb is subsequently parsed. This entails that lexical verbs are parsed from the root node, having a ?Ty $(\mathrm{t})$ trigger, as is the case in siSwati, but not in Swahili or Rangi (we will return to this point below). Another possible development is the loss of the requirement for a locally unfixed node. This means that the auxiliary needs no longer be inflected with a subject marker - as shown above, many auxiliaries in siSwati may drop the subject marker, reflecting this stage. With the possible absence of subject and tense information, auxiliaries at this stage cease to take infinitival complements which, by themselves, do not build rich enough propositional structure to complete the ensuing tree. Furthermore, instead of the mere loss of the requirement for a locally unfixed node, a stronger requirement may result. Since the requirement for a locally unfixed node typically implies that no structure other than a locally unfixed node is present, this implication can be spelled 
out explicitly, so that the IF clause contains a restriction that no structure has been built yet $([\downarrow] \perp)$. Different combinations of these changes reflect different changes in the grammaticalisation of siSwati auxiliaries. The combination of all these developments is only found in the most grammaticalised forms of the system: The alterative marker $s e$ - for example, illustrated in (43) above, merely provides aspectual (specifically alterative) semantics, does not allow prefixation of a subject marker, and does not build any predicate-argument structure. This is reflected in the lexical entry in (55):

$$
\begin{array}{lll} 
& \text { IF } & ? \operatorname{Ty}(\mathrm{t}),[\downarrow] \perp \\
s e- & \text { THEN } & \operatorname{put}(\operatorname{Asp}(\operatorname{ALT})) \\
& \text { ELSE } & \text { abort }
\end{array}
$$

The lexical information from se- thus provides an endpoint of a range of independent processes of lexical change. Through the manipulation of different kinds of lexical information, and the possible combination of different changes of lexical specifications, the DS analysis of auxiliary constructions proposed here allows for the modeling of 1) the change from lexical to grammatical meaning, 2) the change from providing full predicate-argument structure (possibly plus clausal complement, resulting in two propositional, embedded trees), to providing merely underspecified predicate-argument structure, resulting in two partial trees merging into one tree, 3) the change from providing underspecified, skeletal predicate-argument structure to providing a mere annotation of the root node with all structure building done by the main verb, and 4) the change from requiring the presence of a preceding subject marker, to the optional dropping of the subject marker, to the eventual prohibition of any preceding structure.

While there is some overlap with the Swahili and Rangi systems, the siSwati system is exceptionally rich, and the resulting verbal constructions show a wide array of variation. We have thus taken the DS analysis of complex verbal constructions in Swahili and Rangi as a starting point, and extended this analysis to capture different aspects of the grammaticalisation processes underlying the siSwati system. Through this, we have shown how siSwati auxiliaries vary along a cline of development from fully specified, clausal or infinitival complement-taking verbs to, effectively, TAM prefixes like the alterative marker se-. However, a more detailed analysis, in particular of the semantic aspects of the auxiliary system, remains to be undertaken. What the case of siSwati shows however, is that as well as there being variation between languages with regards to the role played by auxiliaries and the complexity of the auxiliary system as a whole, this level of diversity is also attested within a single language where differing grammaticalisation processes have resulted in distinct structural properties.

For the comparative analysis of Swahili and Rangi, a second parameter of variation comes into play, and that is the variation in the trigger statement of lexical entries for verbs and auxiliaries. While in siSwati, all verbs and auxiliaries retain a trigger of ?Ty(t), (i.e. they are parsed from the root node), in Swahili both auxiliaries and verbs are parsed from the predicate node (with a trigger of ?Ty $(\mathrm{e} \rightarrow \mathrm{t})$ ). This entails that a basic predicate frame is built before verbs are parsed, which is done by prefixal TAM morphology (recall that in Swahili all tense-aspect marking involves prefixes). In contrast however, in siSwati both prefixes and suffixes are used, representing the diachronically older situation (cf. Meeussen 1967, Nurse 2008). Under the DS account, innovation in TAM morphology in Swahili - through the grammaticalisation 
of auxiliaries - is related to changes in the lexical triggers of verbs. The lexical verbal trigger in siSwati thus reflects an older system, which can still be detected in the ?Ty $(\mathrm{t})$ triggers of Swahili TAM prefixes. In this respect, Rangi is in between Swahili and siSwati in that Rangi TAM marking is largely prefixal, although the perfect and habitual suffixes remain. Lexical verbs are therefore parsed from a previously built predicate node. However, Rangi auxiliaries differ with respect to their lexical trigger. While $-r i$ is parsed from the predicate node $($ ? Ty $(\mathrm{e} \rightarrow \mathrm{t}))$, $-i j a$ retains the older ? Ty $(\mathrm{t})$ trigger and is parsed from the rootnode.

Transitions between these systems are possible because, while parsing verbs and auxiliaries from the predicate node requires the prior construction of this node, parsing the verb from the root node does not preclude the situation in which the predicate node has already been built. As shown at several points in this paper, as long as the information is consistent, the same node can be built again. The predicate node being built from both a TAM marker or auxiliary and from the lexical verb therefore presents no challenge for the system. Indeed, this is what we assume underlies parses with the Rangi auxiliary -ija and, in the long-term perspective, the transition from the more conservative verbal system of siSwati to the more innovative system of Swahili. The manipulation of different aspects of lexical information, and the general DS stance on underspecification - and in particular the option to rebuild structure as part of the development of semantic interpretations - thus provide the formal tools to explain the variety of auxiliary and modal expressions in siSwati as well as the cross-linguistic variation in auxiliary and complex verbal constructions seen in Swahili, Rangi and siSwati.

\section{Summary and conclusions}

This paper has examined complex verbal constructions in the three Bantu languages Swahili, Rangi and siSwati. Auxiliary constructions in these languages are in many ways representative of the micro-variation found across the Bantu language family (Nurse 2008). Swahili regularly employs a single auxiliary form which is inflected for temporal information, while the auxiliary (-wa 'be') itself merely supplies a metavariable placeholder formula value, but no temporal or aspectual information. In contrast, Rangi employs a number of different auxiliary forms, some of which have temporal information encoded within them, whilst in other instances the auxiliary itself hosts a dedicated tense marker. Finally, the inventory of auxiliaries in siSwati greatly exceeds that found in either Swahili or Rangi, with some 30 forms used to encode different tense-aspect-mood combinations and interpretations. SiSwati also allows for more than one such auxiliary form to be present in a given complex construction which is barred in the other two languages.

We have adopted the tools of the Dynamic Syntax framework in order to bring out and explore issues relating to the combination of temporal and aspectual information across the clause. The analyses we have presented hinge on the concepts of underspecification, accumulation and update. Underspecified information can be introduced at an early stage in the parsing process. This was shown to take the form of structural underspecification in the case of the introduction of unfixed nodes which have an underspecified tree node address and semantic-conceptual underspecification in the case of metavariable placeholders. Accumulation occurs as information is introduced into the parse. This results from lexical input, with each morpheme responsible for the introduction of lexically-specified information which results in distinct contributions to the process of structure building. Finally, update happens as 
additional lexical material contributes to the parse, enabling the resolution of requirements and the update of underspecified values to fully-specified content.

Against this general theoretical background, we have proposed an analysis of Bantu complex verbal constructions in which the auxiliary and main verb jointly build one semantic structure, and where typically the interpretation of the subject is provided by the subject marker of the auxiliary verb, tense-aspect information is provided by both auxiliary and main verb, and the interpretation of the semantic predicate is provided by lexical information from the main verb. The analysis centrally assumes that the same partial tree structure can be built twice (or indeed, more times in the case of siSwati) and that information from different (lexical or pragmatic) sources can be accumulated on one structural node. The option to re-build the same structure is restricted by general constraints on consistency of information holding at any one node, but we have also proposed that, in addition, it may be constrained by lexical conditions. For example, subject markers in Swahili require that no fixed subject node has been built when they are parsed, or if there is such a node, that there also be a predicate variable, thus restricting re-building of structure to auxiliary constructions.

An advantage of the analysis is that it explains the interpretation of subject markers in complex verbal constructions, without stipulating different kinds of subject makers (e.g. some pronoun-like, some agreement-like). The fact that in complex verbal constructions, the two (or more) subject markers necessarily refer to the same subject follows in our analysis from the fact that all subject markers end up providing decorations of the very same node. Once the interpretation of the first subject marker has been fixed by lexical or contextual information, all subsequent subject markers necessarily take the same interpretation, as they trigger the re-building of the same node. The analysis remains essentially pronominal since, even though two different structural contexts in which subject markers can be parsed are distinguished in the lexical entry, the semantic contribution of the subject marker is the same in both contexts: An underspecified pronominal metavariable. There is no lexical distinction between the two contexts in terms of interpretative possibilities. The difference in construal results purely from the structural contexts in which the subject markers are encountered.

Finally, we have shown that auxiliaries in Bantu are part of wider grammaticalisation processes from main verbs to auxiliaries to TAM markers (cf. Botne 1989, Nurse 2008, Gibson 2013). Evidence from siSwati provides a particularly rich illustration of this, and we have shown how our formal analysis can be used to model different stages of grammaticalisation as lexical change, where complex lexical entries of lexical verbs can undergo different changes, typically loss of lexical specifications, and so different uses of auxiliaries and associated constraints result. These include the presence or absence of a preceding subject marker, different temporal-aspectual contributions, different contributions to structure building, and different trigger conditions.

A number of questions remain outstanding, of course. In particular, our analysis of the semantics of tense and aspect is preliminary, and the representation of tense and aspect as predicates of the root node is merely a placeholder for a fuller analysis to be developed. A more semantically transparent analysis of tense and aspect will particularly be useful for the analysis of the semantic shifts involved in the grammaticalisation of the siSwati auxiliary system to show more explicitly the interaction between the lexical semantics of the historical source verb and its eventual aspectual contribution. Another area in which our analysis could be developed further 
is its extension to other forms of complex verbal constructions. We have only briefly mentioned infinitival complements, and have not addressed compound verbs, complex predicates and light verbs, all of which are found in Bantu languages. Beyond Bantu, serial verbs provide another central empirical area against which our analysis and the dynamic perspective on which it is based could be tested. However, we will leave these questions for further research.

\section{References}

Ashton, Ethel O. 1947. Swahili Grammar. 2nd ed. London: Longman.

Blackburn, Patrick and Wilfried Meyer-Viol. 1994. Linguistics, logic and finite trees. Logic Journal of the IGPL 2(1): 3-29.

Botne, Robert. 1989. Reconstruction of a grammaticalized auxiliary in Bantu. Studies in the Linguistics Sciences 19(2): 169-186.

Bresnan, Joan, and Sam A. Mchombo. 1987. Topic, pronoun, and agreement in Chichewa. Language 63: 741-782.

Buell, Leston. 2005. Issues in Zulu verbal morphosyntax. Ph.D. dissertation, UCLA.

Cann, Ronnie 2006. Semantic underspecification and the interpretation of copular clauses in English. In K. von Heusinger and K. Turner (eds.) Where Semantics Meets Pragmatics. Oxford: Elsevier, 307-335.

Cann, Ronnie. 2007. Towards a dynamic account of BE in English. In I. Comorowski, and K. von Heusinger (eds.) Existence: Syntax and Semantics. Dordrecht: Kluwer Academic Publishers, 13-48.

Cann, Ronnie. 2011. Towards an account of the English auxiliary system: Building interpretations incrementally. In Ruth Kempson, Eleni Gregoromichelaki and Christine Howes (eds.) The Dynamics of Lexical Interfaces. Stanford, Cal.: CSLI Publications, 279-317.

Cann, Ronnie, Ruth Kempson and Lutz Marten. 2005. The Dynamics of Language. Syntax and Semantics 35. Oxford: Elsevier.

Carstens, Vicky. 2011. Hyperactivity and Hyperagreement in Bantu. Lingua 121: 721741.

Cole, Desmond T. 1955. An Introduction to Tswana Grammar. London: Longmans and Green.

Diercks, Michael. 2010. Agreement with subjects in Lubukusu. Ph.D. dissertation, Georgetown University.

Doke, Clement M. 1992. Textbook of Zulu Grammar. 6th ed. Cape Town: Maskew, Miller and Longman.

Du Plessis, J.A. and Marianna Visser. 1992. Xhosa Syntax. Pretoria: Via Afrika.

Gibson, Hannah. 2013. Auxiliary placement in Rangi: A Dynamic Syntax analysis. PhD dissertation, SOAS, University of London.

Gregoromichelaki, Eleni. 2006. Conditionals in Dynamic Syntax. PhD dissertation, King's College London.

Henderson, Brent. 2007. Multiple agreement and inversion in Bantu. Syntax 9: 275289.

Kempson, Ruth, Wilfried Meyer-Viol and Dov Gabbay. 2001. Dynamic Syntax: The Flow of Language Understanding. London: Blackwell Publishing.

Marten, Lutz. 2002. A lexical treatment for stem markers in Swahili. Afrikanistische Arbeitspapiere 72: Swahili Forum IX, 87-100.

Marten, Lutz. 2007. Focus strategies and the incremental development of semantic representations: evidence from Bantu. In Enoch Aboh, Katharina Hartmann and 
Malte Zimmermann (eds.) Focus Strategies in African Languages: The interaction of focus and grammar in Niger-Congo and Afro-Asiatic. Berlin/New York: Mouton de Gruyter, 113-135.

Marten, Lutz. 2011. Information structure and agreement: Subjects and subject markers in Swahili and Herero. Lingua 121: 787-804.

Marten, Lutz and Hannah Gibson. 2015. Structure building and thematic constraints in Bantu inversion constructions. Journal of Linguistics. Available on CJO 2015 doi:10.1017/S0022226715000298. Published on-line 14 August 2015.

Meeussen, Achille Emille. 1967. Bantu grammatical reconstructions. Africana Linguistica 3: 79-121.

Ngonyani, Deo. 1998. Towards a typology of applicatives. In I. Maddieson and T. Hinnebusch (eds.). Language History and Linguistic Description in African Linguistics. Trenton, N.J.: Africa World Press, 249-258.

Nichols, Peter. 2011. A morpho-semantic analysis of the persistive, alterative and inceptive aspects in siSwati. $\mathrm{PhD}$ dissertation, SOAS, University of London.

Nurse, Derek. 2008. Tense and Aspect in Bantu. Oxford: Oxford University Press.

Rycroft, David. 1981. Concise SiSwati Dictionary: SiSwati-English, English-SiSwati. Pretoria: J.L. van Schaik.

Schadeberg, Thilo C. 1992. A Sketch of Swahili Morphology. 3rd ed. Cologne: Köppe.

Taljaard, P.C., Khumalo, J.N. and Bosch, S.E. 1991. Handbook of siSwati. Pretoria: J.L. van Schaik.

Thwala, Nhlanhla. 2006. On the subject-predicate relation and subject agreement in SiSwati. Southern African Linguistics and Applied Language Studies 24(3): 331-359.

Zeller, Jochen. 2006. Raising out of finite CP in Nguni: the case of fanele. Southern African Linguistics and Applied Language Studies 24(3): 255-275.

Ziervogel, Dirk and Mabuza, Enoch J. 1976. A Grammar of the Swati Language. Pretoria: J.L. van Schaik. 